\title{
Prediction of Rice Production in the Philippines using Seasonal Climate Forecasts
}

\author{
Naohisa Koide ${ }^{1,4}$, Andrew W. Robertson ${ }^{* 2}$, Amor V. M. Ines ${ }^{2}$, Jian-Hua Qian ${ }^{2}$, \\ David G. DeWitt ${ }^{2}$, Anthony Lucero ${ }^{3}$
}

\author{
Submitted to: \\ Journal of Applied Meteorology and Climatology \\ November 11, 2011
}

\footnotetext{
${ }^{1}$ Quantitative Methods in the Social Sciences Columbia University, New York, NY

${ }^{2}$ International Research Institute for Climate and Society, the Earth Institute at Columbia University, Palisades, NY

${ }^{3}$ Philippines Atmospheric, Geophysical and Astronomical Services Administration, Quezon City, Philippines

4 Japan Meteorological Agency, Tokyo, Japan

*Corresponding author: awr@iri.columbia.edu
} 


\begin{abstract}
Predictive skills of retrospective seasonal climate forecasts tailored to Philippine rice production data at national, regional, and provincial levels are investigated using precipitation hindcasts from one uncoupled general circulation model (GCM) and two coupled GCMs, as well as using antecedent observations of tropical Pacific sea surface temperatures, warm water volume and zonal winds (WWV and ZW). Contrasting cross-validated predictive skills are found between the "dry" January-June and "rainy" July-December crop-production seasons. For the dry season, both irrigated and rainfed rice production are shown to depend strongly on rainfall in the previous October to December. Furthermore, rice-crop hindcasts based on the two coupled GCMs, or on the observed WWV and ZW, are each able to account for more than half the total variance of the dry-season national detrended rice production with about a six-month lead time prior to the beginning of the harvest season. At regional and provincial level, predictive skills are generally low.
\end{abstract}

The relationships are found to be more complex for rainy season rice production. Area harvested correlates positively with rainfall during the preceding dry season, whereas the yield has positive and negative correlations with rainfall in June-September and in October-December of the harvested year respectively; tropical cyclone activity is shown to be contributing factor in the latter three-month season. Retrospective forecasts based on the WWV and ZW are able to account for almost half of the variance of detrended rice production data in Luzon with a few months lead time prior to the beginning of the rainy season. 


\section{Introduction}

Rice is the most important crop for the people of the Philippines. Because the fluctuation in domestic rice production has significant impacts on food security, especially for the poorest people; its year-to-year consistency is a critical concern for the Philippines in terms of food security and the alleviation of poverty (Dawe et al. 2006, 2009).

Paddy rice is known to be one of the most highly susceptible cereal crops to climate variability due to its high water requirements. Relationships between rice and climate are well documented by past research (e.g., Lansigan et al. 2000; Naylor et al. 2001; Selvaraju. 2003; Lansigan 2005; Dawe et al. 2009, Roberts et al. 2009). In the case of the Philippines, much attention has been paid to the El Niño Southern Oscillation (ENSO) because of its large impact on the Philippine climate, and demonstrated impacts of ENSO on the Philippine rice production. For example, Lansigan et al. (2000) indicated that, in El Niño years, rainy-season sowing, that generally occurs around May, could be delayed to mid-August according to the degree of climate variability. Roberts et al. (2009) found different impacts of ENSO on January to June "dry" season and July to December "rainy" season rice production of irrigated and rainfed systems in Luzon respectively; namely a statistically significant relationship between dry-season rice production in Luzon and sea surface temperature (SST) anomalies averaged over the Niño 3.4 region $\left(5^{\circ} \mathrm{N}-5^{\circ} \mathrm{S}, 120^{\circ}-170^{\circ} \mathrm{W}\right)$ for July to September (JAS) of the year before the January-June harvest, but no significant correlations between the July-December rainy season production and Niño 3.4 SST anomalies.

Thus, past research suggests that it may be possible to forecast aspects of Philippine rice production based on climate information alone. Such forecasts could potentially benefit decision making at different levels, from national, regional, and local governments to local farmers (Lansigan, 2005). 
The goal of this paper is to develop seasonal climate forecasts tailored to Philippine rice production for the dry and rainy seasons, at three different spatial scales (national, regional, and provincial level), and to assess and quantify potential predictive skills by means of retrospective forecasts. We apply a cross-validated regression approach in which the predictands are historical records of rice yield, production, or area harvested, and the predictors are selected climate variables. To our knowledge, this is the first comprehensive prediction analysis of the Philippine rice production covering the entire region at national, regional, and provincial levels, and considering both irrigated and rainfed rice systems, with state of the art climate forecasts such as from coupled and uncoupled general circulation models (GCMs).

The paper proceeds as follows. Section 2 describes the rice production and the climate in the Philippines. The datasets used in the paper are described in Section 3. Methodologies and results are presented in Section 4. A summary and discussion are presented in Section 5.

\section{The study region}

\subsection{Rice production}

Rice in the Philippines is typically planted by transplanting seedlings in puddled, bunded fields, where a constant height of water is maintained throughout the growing season. This way of water management provides suitable environment for optimal rice growth and for weed control (de Datta, 1981). Rice production has been increasing for more than five decades through the developments of arable lands, construction of new irrigation systems, improving the performance of existing irrigation systems, and adaptations of new technologies such as modern rice varieties and improved fertilizer usage (Kikuchi et al, 2003). Fig. 1a shows the increasing trend of the annual rice production on top of the inter-annual variability. Fig. $1 \mathrm{~b}$ also shows that the irrigated annual yields started increasing rapidly in the early 1970's and continue to exhibit a strong 
increasing trend, in contrast to the relatively small increasing trend of the rainfed yield for the period. The total area harvested has been increasing due to the creation of new agricultural lands, expanding the irrigated area while that of rainfed systems has been gradually decreasing, caused possibly by its conversion to non-agricultural uses, as shown in Fig. 1c.

Luzon is the main rice producer of the Philippines (Fig. 2a). Most rice-growing regions of Luzon and Mindanao are highly irrigated while regions in the central Philippines consisting of smaller islands still produce about half of their rice with rainfed systems (Fig. 2b). The rainyseason rice in the Philippines is planted at the onset of the summer monsoon which generally occurs in May. The planting of dry-season rice follows right after the harvest of the rainy-season rice for utilization of rainfall at the end of the rainy season (Roberts et al. 2009).

\subsection{Climate}

The Philippines, consisting of 7107 islands, is within the Western North Pacific (WNP) southwest summer and northeast winter monsoons domain (Wang and Ho 2002). The Philippine climate is widely different by region due to its complex topography, classified into four types defined by the Philippines Atmospheric, Geophysical and Astronomical Services Administration (PAGASA). Type I has a distinct summer monsoonal wet season from May to October and a dry season from November to April. Most western regions belong to this type. Type II, on the contrary, has no clear dry season, and maximum rainfall in November to December associated with the northeast winter monsoon. Most of the north-eastern regions are categorized into this type. Type III is an intermediate band of Type I and II. It has maximum rainfall from May to October with unclear but relatively dry season from November to April. Most southern areas belong to Type IV which has evenly distributed rainfall throughout the year (Fig. 3a, 3b). Moron et al. (2009) also classified the Philippine rainfall patterns into two groups using a k-means 
clustering method; a west coast region with clear dry seasons from November to April and eastern coast regions without a dry season during the period.

Several previous studies have addressed the mechanisms and the predictability of the summer monsoon and its onset over the northwest Pacific and the Philippines during May-June (e.g., Wang and Ho 2002; Akasaka et al. 2007; Moron et al. 2009). Inter-annual variability of the Philippine climate is dominated by ENSO. PAGASA summarizes the potential impacts as follows: during the warm (cold) phase of ENSO: 1) the rainy season is shorter (longer) due to the delayed (normal or early) monsoon onset and the early (normal or late) termination, 2) weak (strong) monsoon activity, 3) less (more) cyclones pass through the Philippines, 4) below (above)

normal rainfall, and 5) above (below) normal temperature. More recently, however, Lyon and Camargo (2009) revealed a seasonal reversal in the ENSO rainfall signal over the Philippines between July-September (JAS) and October-December (OND); below (above) average rainfall in JAS and above (below) average rainfall in OND during warm (cold) phase of ENSO. A warm (cold) phase of ENSO induces drier (wetter) conditions in OND in almost the entire region with especially stronger impacts on the central Philippines. Significant positive correlations between several stations in the central Philippines with Niño 3.4 index are observed in JAS. It is revealed that the development of the low-level westerlies over WNP during the boreal summer, through the enhancement of WNP summer monsoon, increases the rainfall around the region (Lyon and Camargo 2009).

\section{Data}

\subsection{Rice data}

National, regional and provincial data on rice production, yield and area harvested of irrigated systems, rainfeds system, and all ecosystems, from 1970 to 2007 were downloaded from 
the Philippine Rice Statistics e-Handbook published as a collaborative project of the Philippine Rice Research Institute and the Philippines' Bureau of Agricultural Statistics (http://dbmp.philrice.gov.ph/Ricestat/Statmonth\%20data/index.html). The Philippines has 17 administrative regions (Fig. 3b) and 80 provinces, while this dataset includes 16 administrative regions (NCR is not available) and 73 provinces. Here, all ecosystems include irrigated systems, rainfed systems, as well as high lands. However rice production in the high lands, is negligible and is thus not considered in this study. This dataset is partitioned into two seasons, January-June and July-December, which approximately correspond to the periods of rice harvest for dry and rainy season respectively. Rice data for January-June and July-December are referred to as dryseason and rainy-season rice data respectively hereafter. Because of nonexistence of regional data for REGION I, IX, XI, and XII (Fig. 3b), they were calculated from available provincial data. Note that REGION IX, XI, and XII rice data are incomplete due to the lack of provincial data: provincial rice data for Zamboanga Sibugay in REGION IX, Compostela Valley in REGION XI, and Sarangani and South Cotabato in REGION XII are not available. Rice data for REGION IV were decomposed to REGION IV-a and IV-b using the provincial rice data; rice data for REGION IV-b were obtained as the difference between those for REGION IV and those for REGION IV-a which were calculated from the provincial data. The rice data for 1970-1976 were not used in the correlation analysis with rainfall, nor in the predictability analysis, because of unavailability of many of the climate data records and forecasts for the period.

\subsection{Climate data}

A 77-station network of daily rainfall observations from 1977 to 2004, obtained from PAGASA, is used in the paper (Fig. 3(a)). For filling missing values, the same method as Moron et al. (2009) was applied; a simple weather generator with a gamma distribution was applied to 
each station individually, with parameters estimated for each calendar month separately. A wet day is defined here as a day with more than $1 \mathrm{~mm}$ of rainfall.

Niño 3.4 index from 1969 to 2008 calculated by the Climate Prediction Center U.S. National Oceanic and Atmospheric Administration (NOAA) and an index of equatorial Pacific heat content, the integrated warm water volume (WWV) above the $20^{\circ} \mathrm{C}$ isotherm averaged between $5^{\circ} \mathrm{N}-5^{\circ} \mathrm{S}, 120^{\circ} \mathrm{E}-80^{\circ} \mathrm{W}$ (Meinen and McPhaden, 2000) from 1980 to 2008 , calculated by TAO (Tropical Atmosphere-Ocean) of NOAA, were used as empirical predictors. Data on tropical cyclones (TCs) for the period 1977 to 2007 were downloaded from the US Navy's Joint Typhoon Warning Center Western North Pacific Best Track Data. In the study, only TC data within $100 \mathrm{~km}$ of the coastline of the Philippines were used. Surface zonal wind (ZW) anomalies averaged between $2^{\circ} \mathrm{S}-2^{\circ} \mathrm{N}, 180^{\circ} \mathrm{E}-220^{\circ} \mathrm{E}$ for the period 1980 to 2008 , were also used as predictors and obtained from DASILVA: Atlas of Surface Marine Data 1994 and TOGA-TAO Array respectively.

\subsection{Seasonal prediction models}

For predictability analysis and building forecast models for rice, we used retrospective seasonal climate forecasts made with three general circulation models (GCMs): the Max-Planck Institute ECHAM4.5 atmospheric GCM (AGCM) (Roeckner et al. 1996) forced with empirically predicted constructed analog (CA) SSTs (ECHAM-CA hereafter) (Van den Dool 1994; Li et al. 2008), with 24 ensemble members from 1981 to 2007; the NOAA National Centers for Environmental Prediction (NCEP) Climate Forecast System version 1 (CFS), a fully coupled

ocean-land-atmosphere dynamical seasonal prediction system (Saha et al. 2006), with 15 ensemble members from 1981 to 2007, and a coupled GCM consisting of the ECHAM4.5 AGCM and the Geophysical Fluid Dynamics Laboratory (GFDL) Modular Ocean Model Version 
3 (MOM3; Pacanowski and Griffies, 1998) with 9 ensemble members from 1982 to 2007 (ECHAM-MOM hereafter) (DeWitt 2005). For each GCM, the ensemble mean over all the available ensemble members was taken at the outset.

\section{Methodology}

\subsection{Detrending and normalization of rice data}

Rice production is influenced by non-climatic factors such as changes in technology. Here, we assumed that non-climatic factors influence rice production at lower frequencies and that such trends can be removed from the rice data time series using a low pass spectral smoothing filter, leaving those signals influenced by climate. We used a Butterworth low-pass filter with 10-year cut off period to de-trend the rice data. The cut off period was chosen based on similar published and non-published studies (e.g. Baigorria et al. 2008). Running averages of 7 , 9, and 11 years were also calculated, leading to similar results to those with the Butterworth filter. Residuals of rice data were then calculated as deviations from the trend divided by the trend [(observed value - trend $) /$ trend $]$.

The distribution of the rice-data residuals of rice data often departs from normality. Prior to the correlation analysis with climate variables, a Box-Cox transform (Box and Cox 1964) was applied to the residuals of rice data to correct the departures from normality. However, very similar results were obtained without the Box-Cox transform (not shown). Prior to regression model building, a quantile-quantile mapping of the empirical distribution to a normal deviate was used to normalize of the rice-data residuals (with no Box-Cox transformation).

\subsection{Measures of spatial coherence of station rainfall}

Previous studies have shown that the spatially coherent component of seasonal rainfall 
anomalies at the station scale in the tropics (Haylock and McBride 2001; Moron et al. 2006; Moron et al. 2007) and the Philippines (Moron et al. 2009) tends to reflect the impact of large scale climate forcings such as ENSO; higher spatial coherence thus tends to indicate higher seasonal predictability. Two different measures are used here as the indicators of spatial coherence on station rainfall, namely the inter-annual variance of standard anomaly index (SAI; Katz and Glantz 1986), and the number of degrees of freedom (DOF; Fraedrich et al. 1995). The DOF estimates the number of independent variables in a dataset in terms of empirical orthogonal functions (EOFs); higher (lower) values represent lower (higher) spatial coherence. The SAI is defined as the average of the normalized station time series of seasonal averages over the 77 stations. The inter-annual variance of SAI, $\operatorname{var}(\mathrm{SAI})$, is an alternative measure of spatial coherence to the DOF. For example, if seasonal rainfall between all stations are perfectly correlated, $\operatorname{var}(\mathrm{SAI})$ is 1 ; if seasonal rainfall of all stations are independent, $\operatorname{var}(\mathrm{SAI})=1 / \mathrm{M}$ where $\mathrm{M}$ is the number of stations (Katz and Glantz 1986; Moron et al. 2006). The DOF and $\operatorname{var(SAI)~are~consistent~estimators~of~spatial~coherence~(Moron~et~al.~2007).~}$

\subsection{Regression models and predictor variables}

Regression models were built for national rice production using various climate variables as predictors. These models were then tested under cross-validation, with 5-year contiguous samples withheld for developing the regression equation, and the forecast validated for the central year of the withheld years. The additional omission of the years on either side of the forecast year guards against leakage of the signal from adjacent years.

Three different types of linear regression models were used: Multiple Linear Regression (MLR), Principal Component Regression (PCR), and Canonical Correlation Analysis (CCA). PCR is a regression analysis for a univariate predictand which uses a subset of principal 
components (PCs) of the predictor set, so as to account for a large fraction of the predictor variance within a few independent components. CCA is a multivariate statistical method to identify linear relationships between two sets of multidimensional variables, based on lowdimensional PC subsets of both predictor and predictand datasets (Barnett and Preisendorfer 1987; Barnston and Smith 1996). Through the use of a small set of PCs as predictors, both PCA and CCA overcome problems with multicollinearity between predictors and the multiplicity arising from high-dimensional predictor fields. Here, the PC subsets selected for PCR and CCA were determined so as to maximize the average skill under cross-validation. All the analyses were performed using the Climate Predictability Tool (CPT) software (http://portal.iri.columbia.edu/portal/server.pt).

Climate variables selected as empirical predictors are the Niño 3.4 index, and the bivariate index consisting of WWV and ZW (Sect. 3.2). The WWV and ZW anomalies play key roles in the ENSO cycle, with El Niño events being accompanied by positive WWV and ZW anomalies (Izumo et al. 2010); we refer to it as "WWV and ZW" in the following. In addition to these empirical ENSO indices, we also use the ensemble-mean forecasts of seasonally-averaged gridded precipitation over the Philippines $(0 \mathrm{~N}-25 \mathrm{~N}, 110 \mathrm{E}-130 \mathrm{E})$ from the three GCMs, i.e. the ECHAM-CA, ECHAM-MOM, and CFS.

Climatological base periods used for CPT analysis are 1981-2007 for WWV and ZW, 1981-2006 for ECHAM-CA, 1982-2007 for CFS, and 1983-2007 for ECHAM-MOM.

\section{Results}

\subsection{Spatial coherence and potential predictability of rainfall}

Figure 4 shows the potential predictability of Philippines station rainfall in terms of the spatial coherence of seasonal amount $(S)$, occurrence or number of wet days $(O)$, and mean 
intensity on wet days $(I)$. Thus, seasonal amount $(S)=$ occurrence $(O) *$ mean intensity of wet days (I). Both the var (SAI) and DOF indicate a higher spatial coherence of $S$ and $O$ from September-November (SON) through April-June (AMJ), followed by lower coherence from May-July (MJJ) through August-October (ASO). These two half-years coincide with the main dry and rainy seasons respectively. On the contrary, the spatial coherence of $I$ is low throughout the year, suggesting lower potential predictability of mean rainfall intensity throughout the year.

The seasonal cycle of correlations between the SAI of $S, O$, and $I$ and the Niño 3.4 index is shown in Fig. 5. All three rainfall average quantities are negatively correlated with Niño 3.4 index $(\mathrm{p}<0.05)$ from SON to AMJ when spatial coherence of $S$ and $O$ is high. Reversal of correlation between ENSO and rainfall was also found from JAS through ASO, though the correlations with Niño 3.4 index are not statistically significant. It is interesting to note that the strength of correlation of mean intensity with ENSO is comparable to that of rainfall frequency while the spatial coherence of mean intensity is much lower that of rainfall occurrence frequency.

The above analysis clearly shows the distinct difference in potential predictability of rainfall in the Philippines between the dry and rainy season. Rainfall in the dry season, with high spatial coherence and strong negative correlations with the Niño 3.4 index, is potentially predictable while that in the rainy season, with low spatial coherence and weak positive correlations Niño 3.4 index, is less predictable. A similar relationship between spatial coherence, predictability, and ENSO has also been found in Indonesia (Haylock and McBride 2001; Moron et al., 2009).

\subsection{Dry season predictability (January-June)}

\section{a. Relationship between rice production and rainfall}

For the purpose of identifying the rainfall season maximally correlated with dry-season 
(January-June) rice production, we first explored lag correlations between national rice production, yield and area harvested and SAI of $S$ from year (-1) to year (0) (Fig. 6). The SAI of the 77 stations explains about the same proportion of total variances as the first principal component (PC), namely the dominant mode of the inter-annual variability of the Philippine rainfall. Hereafter, we focus on the lag correlation with SAI of $S$ only. For both irrigated and rainfed systems, the peak correlations of the national rice production, yield, and area harvested with the SAI were found a few months before the beginning of the harvest period, i.e. OND of year(-1), which approximately coincides with the planting period. Such high correlations $(r>0.7$ $\sim 0.8, \mathrm{p}<0.01)$ suggest that total amount of OND rainfall is a critical climatic factor for dryseason rice planting in the Philippines. Similar but overall slightly weaker 3-year lag correlations with SAI of $O$ and $I$ were also found (not shown).

The peak correlations of the national rainfed yield and area harvested of rainfed systems with the SAI are higher than those of irrigated system. Such difference between the two systems might be related to the closer dependence of rainfed system on rainfall. Higher sensitivity of rainfed systems in the dry season to rainfall than irrigation systems were also observed in Roberts et al. (2009).

At the regional level, correlations of rice production, yield and area harvested of each system with the SAI (pink lines in Fig.6) are generally weaker than those at the national level, while they have also peaks of positive correlations with the SAI in OND similarly at the national level. Higher dependences of rainfed systems on rainfall than irrigated systems are also observed in most regions.

\section{b. Predictability of dry-season rice production}

\section{(i) National level}


As shown in the previous section, inter-annual variability of national dry-season rice production of irrigated and rainfed rice systems strongly s on rainfall from October of year (-1) to March of year (0) (Fig. 6). High predictability of rainfall during the period as well as its strong dependence on ENSO shown in Figs. 4 and 5 suggest potential predictability of dry-season rice production with climate information. To examine predictive skills in the rice production, we first identified the best predictors for the national rice production of all ecosystem based on crossvalidation, considering three-month averages (at various lead times) of the Niño 3.4 index, WWV and ZW, as well as predicted precipitation over the Philippines from the three GCMs.

Figure 7 shows the cross-validated anomaly correlation skill based on these threemonthly predictors at various lead times. In the case of the empirical predictor indices, the correlation values in Fig. 7 for a particular month indicate the skill of the MLR model using the predictors averaged over the previous three month period, and the following January-June rice production as the predictand. Thus, for a forecast made in June, the predictors are averaged over the preceding MAM period. In the case of the GCMs, PCR is used with the GCM's predicted gridded precipitation field over the Philippines $\left(110^{\circ} \mathrm{E}-130^{\circ} \mathrm{E}, 0^{\circ} \mathrm{N}-25^{\circ} \mathrm{N}\right)$ as predictor. Here a predictive skill of the GCM, for a particular forecast time, uses GCM forecasts of OND precipitation initialized on the $1^{\text {st }}$ of the month; e.g., the predictive skill in June is based on PCR of the GCM's OND precipitation anomalies in OND over the Philippines, predicted on $1^{\text {st }}$ June, together with the following January-June rice production as the predictand.

The results in Fig. 7 clearly demonstrate that the combination of WWV and ZW shows very high predictive skills $(r>0.7)$ even half a year before the beginning of the harvest period. The two coupled models show just as high predictive skills as those of WWV and ZW, and maintain these high skill levels even when initialized in June of the year (-1). In other words, more than half of the total variance of the national rice production in the dry season can be 
predicted several months prior to the planting, which generally takes place around October of year (-1). On the contrary, the predictive skill of Niño 3.4 index and the uncoupled model, ECHAM-CA decreases gradually as the lead time increases, and falls below 0.4 by half a year of lead time.

The longer-lead predictive skills obtained using the two coupled GCMs and the WWV and ZW, as compared to those of the uncoupled GCM and Niño 3.4 index, are consistent with the respective skills of these models and predictors when applied to prediction of OND rainfall over the Philippines (details are not shown here).

Figure 8 shows the time series of cross-validated retrospective forecasts of national dryseason all-ecosystem rice production anomalies versus the observed, obtained using PCR of OND precipitation forecasts from the coupled GCMs initialized on June 1 of year (-1). Both coupled models capture well the inter-annual variability of the dry-season production including the large negative anomalies accompanying the 1982-1983 and 1997-1998 El Nino events. We also examined the relative operating characteristics (ROC) curve (Swets 1973; Mason and Graham 1999) in order to assess their forecasting capabilities for the above/below normal rice production in a probabilistic context (Fig. 9). The areas beneath the ROC curve for forecasting the below (above) normal rice production with the OND precipitation anomalies of CFS and ECHAM-MOM are $0.81(0.84)$ and $0.82(0.75)$ respectively, substantially exceeding the climatological expectation of 0.5 . Both coupled GCMs have good ability to predict above/below normal national rice production in the dry season.

(ii) Regional and provincial level

Next, we examined the predictive skills of dry-season rice production of all ecosystem, irrigated system, and rainfed system at the regional and provincial level. Here we conducted 
cross-validated CCA using the predicted ensemble total precipitation anomalies over the Philippines in OND from 1982 to 2007 by ECHAM-MOM initiated on $1^{\text {st }}$ June as predictors. Similar results were obtained using the CFS.

For both regional irrigated and rainfed rice production (therefore for all ecosystem also), statistically significant $(\mathrm{p}<0.05)$ forecast skill is limited to several regions in the central Philippines (REGION VI, VII, and VIII for irrigated system and REGION IV-b, V, VI, and VII for rainfed system) as well as REGION XII and ARMM in the southern Philippines (Mindano) (Fig. 10a). A fairly similar pattern of correlation skill was obtained at the provincial level (Fig. 10b). Detailed comparison of predictive skills between the regional and the provincial level is unfortunately difficult due to limited availability of provincial data. Overall, predictive skills at regional and provincial levels are lower than those at the national level.

\subsection{Rainy season predictability (July-December)}

\section{a. Relationship between rice production and rainfall}

In contrast to the dry season, rainy-season rice yield and area harvested correlate with rainfall in a complex manner (Fig. 11). The national area harvested of the irrigated rice system correlates quite highly with the SAI of $S$ from around SON of year (-1) to MJJ of year (0) (Fig. 11f); thus, more rainfall during the preceding dry season results in increase in irrigated area harvested for the following rainy season. At the regional level (Fig. 11, pink curves), positive correlations of rainy-season irrigated area harvested with rainfall during the preceding dry season were also found in most regions, although the correlations are often weak (Fig. 11f). The above results suggest national scale climatic impacts, possibly caused by ENSO, on the rainy-season irrigated area harvested during the period. On the contrary, the rainfed area harvested has a positive but weaker correlation with the rainfall during the preceding dry season except for the 
significant peak around MJJ (Fig. 11j).

With regard to the national yield, positive correlations of the irrigated yield with the SAI (Fig. 11e) are found from MJJ to JAS of year (0), which rapidly turns into significant negative correlations by SON of year (0). The rainfed yield correlation (Fig. 11h) has a sharp peak in JAS of year (0) which also turns into the negative correlations by the end of the year. At regional level, both irrigated and rainfed yields in most regions have insignificant positive correlations (say, $\mathrm{r} \sim 0.2$ to 0.3 ) around JJA at $95 \%$ confidence level. However, only yields of a spatially confined region, namely the irrigated yield of REGION III, IV-a, and V (Fig. 12(a)) and the rainfed yield of REGION III have significant negative correlations $(p<0.05)$ with the SAI in OND. Since all regions whose yields negatively correlated with the SAI are located in the northcentral Philippines, such spatial correlation patterns may result from some climatic impacts affecting only the north Philippines during the period, such as tropical cyclones causing flood and wind damages to rice crops.

\section{b. Impact of tropical cyclones}

The Philippines rice production is severely affected by tropical cyclones (Lansigan 2005). Since most tropical cyclones pass over the central and northern Philippines, their impact is expected to be largest there. In order to examine impacts of tropical cyclone activity on the rainy season yields, we introduced accumulated cyclone energy (ACE; Bell et al. 2000) as an index of tropical cyclone activity because of its usefulness for correlation and regression analysis with the other climate variables (Camargo and Sobel 2005; Camargo et al 2007). The ACE is defined as the sum of the squares of the estimated 6-hourly maximum sustained wind speed in which the cyclone is either a tropical storm or greater (tropical depressions are not included in this analysis); it accounts for the number, intensity, and duration of tropical cyclones during a given 
typhoon season, all of which are likely to have impacts on rice production. In this study, we used ACE within $100 \mathrm{~km}$ of the coast of the Philippines during the main tropical cyclone season in the Philippines, from July through December (Lyon and Camargo 2009), for the period, 1977-2007. Interannual variability of July-December ACE exhibits statistically significant $(\mathrm{p}<0.05)$ negative correlations with irrigated yields of REGION IV-a, IV-b, and V (Fig. 12b), and the rainfed yields of REGION IV-a and V (not shown). Weak negative correlations were also found in both irrigated and rainfed systems only in the northern part of the Philippines (CAR, REGION II, and III), though they are not statistically significant at 95\% confidence level.

Differences in impacts of tropical cyclones occurring during JAS vs. OND were also examined. The ACE in OND has negative correlations $(\mathrm{p}<0.05)$ with the irrigated yields of CAR, REGION III, IV-a, IV-b, and V as well as the rainfed yield of REGION III, IV-b, and V, whereas no significant correlations with the ACE in JAS were found; thus, tropical cyclones mainly impact rainy-season rice yields during OND. It is interesting to note that SAI of $S$ in OND and the ACE in OND have significant negative correlations with the irrigated and rainfed yields only around the central Philippines although their detailed patterns are different.

\section{c. Predictability of rainy-season rice production}

\section{(i) National level}

As shown in Sects. 5.3a-b, we found positive correlations between the rainy-season area harvested, especially in irrigated systems in most regions across the country, and the rainfall during the preceding dry season, as more water is stored in reservoirs or more streamflow supporting run-of-the-river irrigation systems. Rainy-season yields are negatively correlated with the SAI of rainfall and tropical cyclone ACE mainly in OND, and especially in irrigated systems in the north-central Philippines, while positive correlations with the SAI of rainfall in JAS were 
observed in rainfed system.

Following the same procedure of regression model building used in Sect. 5.2b, we examined the predictive skills of WWV and ZW, in addition to Niño 3.4 index (Fig. 13). We did not attempt to use the GCM hindcasts of precipitation because of the complex relationship between rice and rainfall. Predictive skills of WWV and ZW are relatively constant at around 0.5 to 0.6 throughout the first half of the calendar year, with a peak at the beginning of March (namely WWV and ZW in DJF). Fig. 14 shows the retrospective forecast anomalies of rainyseason all-ecosystem national production versus the observed, using WWV and ZW in DJF as predictors. The inter-annual variability is well captured using these DJF predictors which precede the sowing season for rainy-season production which generally takes place around April to May.

\section{(ii) Regional and provincial level}

Predictive skills of WWV and ZW in DJF in rainy-season rice production at regional and provincial levels were also investigated using MLR for each region and province individually (Fig. 15). For both irrigated and rainfed rice production, most regions in Luzon have significant predictive skills while most of the other regions do not. Regional yields in the rainy season show a similar spatial pattern of predictive skills whereas harvested area does not (not shown). Predictive skills in Luzon-average rice production are also plotted in Fig. 13, which demonstrates that Luzon rainy-season rice production is generally more skillful than for the Philippines as a whole, with a peak of about $r=0.7$ in March. Fig. 16 shows a ROC diagram for rainy-season Luzon rice production. The areas beneath the ROC curve for predicting the below (above) normal rice production in Luzon with WWV and ZW in DJF are 0.74(0.72) respectively, indicating the good ability to predict above/below normal rainy-season Luzon rice production from the previous March. 


\section{Summary and Discussion}

The aim of this study was to assess the predictive skills of state of the art seasonal climate forecasts, such as coupled GCMs, in prediction of the Philippines rice production, in order to explore their potential for decision makings at different levels from national policy makers to local farmers. To this end, cross-validated predictive skills in the rice production were calculated at national, regional, and provincial levels using retrospective GCM forecasts of precipitation, and indices of observed antecedent equatorial SST, warm water volume and zonal winds.

The spatial coherence of seasonal anomalies of observed station rainfall in the Philippines was first investigated in order to assess the potential predictability of rainfall at local scales. This analysis demonstrated a clear contrast in the rainfall predictability between the dry season and rainy season: in the Philippines, seasonal anomalies of dry-season precipitation are found to be highly spatially coherent between stations (potentially predictable) (Fig. 4), and ENSO is strongly anti-correlated with seasonal rainfall attributes (Fig. 5). A lag correlation analysis (Fig. 6) revealed a strong dependence of the dry-season yields, areas harvested, and rice production, on rainfall toward the end of rainy season and beginning of dry season, namely the sowing season for dry-season rice crop around October; at that time the correlation with the rainfall reaches a maximum of around 0.8 at the national level, obtained by summing up regional production figures. Weaker but common responses to climatic signals in dry-season rice production at the regional level (Fig. 10) reinforce each other at the national level, with the result that summing up of regional production cancels other spatially random variability of rice production, which may be mainly due to non-climatic factors. Weak correlations between dryseason rice production at provincial and regional level and rainfall might suggest failures of 
removing non-climatic factors at those levels using the low-pass filter, and therefore the importance of consideration of inter-annual socio-economic influences at seasonal to inter-annual frequencies. If that is the case, skillful forecasting systems of rice production at spatially finer scales might need to reproduce such seasonal to inter-annual variability of rice production due to non-climatic factors, for instance, by integrating economical and/or crop models.

This study found high predictive skills using CFS, ECHAM-MOM coupled GCM forecasts of Philippines precipitation, and antecedent observed WWV and ZW indices in the dry season rice production, sufficient to forecast more than half of total variances of the dry-season rice production of the Philippines with about half a year lead time from the beginning of the harvest (Fig. 7). Such high predictive skills of climate forecasts encourages development of a forecasting system for decision making on food security of the Philippine government, the only authority to import rice (Dawe et al. 2006), to ensure food security by better controlling amount of imported rice.

The results for the rainy-season rice production, on the contrary, are more complex. Relations of the areas harvested with rainfalls differ from those of the yields: while the areas harvested in most Regions have positive correlations with the rainfall in the precedent dry season, rainfalls during the latter period of rainy season negatively affect the rainy-season yields of the central-north Philippines (Fig. 11). The ACE analysis showed a strong impact of tropical cyclone activity on rainy-season yields in the central to northern Philippines (Fig. 12b). It is interesting to note that the correlation patterns of rainfall and ACE in OND with yields are somewhat different. The impacts of tropical cyclones on rice production may be due to rainfall, flooding, or strong winds, or some combination thereof; since these impacts are still not well understood, detailed analysis is encouraged as a topic for future research.

Such complexity of relationships between rice and meteorological conditions during the 
rainy season makes it difficult to select appropriate predictors. In the study, WWV and ZW was selected for assessment of the predictive skills. The contrast in obtained patterns of predictive skills between the northern Philippines and the other regions are remarkable. Regions with high predictive skills in rice production are mostly confined to the central to northern Luzon, and it well corresponds to the pattern of predictive skills in yields (not shown). Note, however, that this pattern is different from correlation patterns of the rainy-season yields with rainfall and tropical cyclones (Fig. 12). Careful analysis, including possibility that we might miss some meteorological factors influencing the rainy-season yields, is needed for investigation of this difference. Some of candidates for such missing factors might be timing of onsets and/or strength of the monsoon, considering that most of the Philippines are located within the western North Pacific (WNP) boreal summer monsoon region which is part of the broad-scale Asian-Pacific southwest monsoon system (e.g., Wu and Wang 2000; Wang et al. 2001; Wang and Ho 2002).

The paper clearly showed high potential of crop forecasting just based on climate forecasts, but at the same time, its limitations at regional and provincial levels. In the real world, crop production depends on both climatic and non-climatic factors. Mishra et al. (2008) demonstrated better performance of crop simulation models driven by seasonal rainfall forecasts at station level than that with statistical models with climate variables as predictors. Validation of performance of crop models driven by forecasted climate variables with GCMs in the Philippines is encouraged to examine whether or not crop models improve forecasting skills at regional and provincial levels.

The methodologies used in this paper demonstrated the utility of: i) identifying seasons and areas whose precipitation is potentially predictable using spatial coherence analysis, ii) exploring impacts of the predictable precipitation on crop production, and iii) selecting season and areas of crop production to maximize predictive skills of climate forecasts. In the paper, 
maximized predictive skills were obtained in the dry season at the national scale. Note that dryseason precipitation is spatially coherent across the country and most Regions share common features of correlations with precipitation. Testing this approach in other countries could give more thoughts on usability of this methodology.

Acknowledgments: The authors thank the Philippine Atmospheric Geophysical and Astronomical Services Administration (PAGASA) for providing the daily rainfall records. This work was funded by NOAA under a cooperative agreement with the IRI. The computing for the GCMs run at IRI used in this project was partially provided by a grant from the NCAR CSL program to the IRI. 


\section{REFERENCES}

Akasaka I., Morishima W., Mikami T., 2007: Seasonal march and its spatial difference of rainfall in the Philippines. Int J Climatol 27, 715-725.

Baigorria, A. G., J.W. Hansen, N. Ward, J. W. Jones, J. J. O’Brien, 2008: Assessing Predictability of Cotton Yields in the Southeastern United States Based on Regional Atmospheric Circulation and Surface Temperatures. J. Appl. Meteor., 47, 76-91.

Barnett, T. P., and R. Preisendorfer, 1987: Origins and levels of monthly and seasonal forecast skill for U.S. surface air temperatures determined by canonical correlation analysis. Mon. Wea. Rev., 115, 1825-1850.

Barnston, A. G., and H. M. van denDool, 1993: A degeneracy in cross-validated skill in regression-based forecasts. J. Climate, 6, 963-977.

— , and T. M. Smith, 1996: Specification and prediction of global surface temperature and precipitation from global SST using CCA. J. Climate, 9, 2660-2697.

Bell, G. D., and Coauthors, 2000: Climate assessment for 1999.Bull. Amer. Meteor. Soc., 81, S1S50.

Box, G. E. P., and D. R. Cox, 1964: An analysis of transformations. J. Roy. Stat. Soc., 127A, $211-252$. 
Camargo, S. J., and A. H. Sobel, 2005: Western North Pacific tropical cyclone intensity and ENSO. J. Climate, 18, 2996-3006.

—, A. W. Robertson, S. J. Gaffney, P. Smyth, and M. Ghil, 2007: Cluster analysis of typhoon tracks. Part II: Large-scale circulation and ENSO. J. Climate, 20, 3654-3676.

Dawe, D., P. Moya, and C. Casiwan, 2006: Why Does the Philippines Import Rice? Meeting the Challenge of Trade Liberalization. International Rice Research Institute, $165 \mathrm{pp}$.

_,_, and S. Valencia, 2009: Institutional, policy and farmer responses to drought: El Niño events and rice in the Philippines. Disasters, 33, 291-307.

de Datta, S.K. 1981. Principles and practices of rice production. John Wiley and Sons. 619 pp.

DeWitt, D. G., 2005: Retrospective forecasts of interannual sea surface temperature anomalies from 1982 to present using a directly coupled atmosphere-ocean general circulation model. Mon. Wea. Rev., 133, 2972-2995.

Fraedrich, K., C. Ziehmann, and F. Sielmann, 1995: Estimates of spatial degrees of freedom. $J$. Climate, 8, 361-369.

Haylock, M., and J. McBride, 2001: Spatial coherence and predictability of Indonesian wet season rainfall. J. Climate, 14, 3882-3887. 
Izumo, T., J. Vialard, M. Lengaigne, C. B. Montegut, S. K. Behera, J.-J. Luo, S. Cravatte, S. Masson, and T. Yamagata, 2010: Influence of the state of the Indian Ocean Dipole on the following year's El Niño. Nature Geosci., 3, 168-172.

Katz, R. W., and M. H. Glantz, 1986: Anatomy of a rainfall index. Mon. Wea. Rev., 114, 764771.

Kikuchi, M., Maruyama, A., and Hayami, Y., 2003: Phase of Irrigation Development in Asian Tropics: A Case Study of the Philippines and Sri Lanka. The J. of Dev. Studies. 39, 109-138.

Lander, M. A., 1996: Specific tropical cyclone tracks and unusual tropical cyclone motions associated with a reverse-oriented monsoon trough in the western North Pacific. Wea. Forecasting, 11, 170-186.

Lansigan, F. P., 2005: Coping with climate variability and change in rice production systems in the Philippines. Rice is Life: Scientific Perspectives for the 21st Century: Proceedings of the World Rice Research Conference, Tsukuba, Japan, K. Toriyama, K. L. Heong, and B. Hardy, Eds., International Rice Research Institute, 542-545.

-, W. L. de los Santos, and J. O. Coladilla, 2000: Agronomic impacts of climate variability on rice production in the Philippines. Agric. Ecosyst. Environ., 82, 129-137.

Li, S., L. Goddard, and D. G. DeWitt, 2008: Predictive skill of AGCM seasonal climate forecasts 
subject to different SST prediction methodologies. J. Climate, 21, 2169-2186.

Lyon B., Camargo S., 2009: The seasonally varying influence of ENSO on rainfall and tropical cyclone activity in the Philippines. Clim Dyn 32, 125-141.

Mason, S. J., and N. E. Graham, 1999: Conditional probabilities, relative operating characteristics, and relative operating levels. Weather and Forecasting, 14, 713-725.

Meinen, C.S. and M.J. McPhaden, 2000: Observations of warm water volume changes in the equatorial Pacific and their relationship to El Niño and La Niña, J. Clim., 13, 3551-3559.

Mishra, A., Hansen, J.W., Dingkuhn, M., Baron, C., Traore, S.B., Ndiaye, O., Ward, M.N., 2008: Sorghum yield prediction from seasonal rainfall forecasts in Burkina Faso. Agricultural and Forest Meteorology, 148, 1798-1814.

Moron, V., A. W. Robertson, and M. N. Ward, 2006: Seasonal predictability and spatial coherence of rainfall characteristics in the tropical setting of Senegal. Mon. Wea. Rev., 134, $3468-3482$.

_,_,_, and P. Camberlin, 2007: Spatial coherence of tropical rainfall at regional scale. J. Climate, 20, 5244-5263.

—, A. Lucero, F. Hilario, B. Lyon, A. W. Robertson, D. DeWitt, 2009: Spatio-temporal variability and predictability of summer monsoon onset over the Philippines. Clim Dyn 33, 
1159-1177.

Moron, V., A. W. Robertson and R. Boer, 2009: Spatial coherence and seasonal predictability of monsoon onset over Indonesia. J. Climate 22, 840-850.

Naylor, R. L., Falcon, W. P., Rochberg, D., and Wada, N., 2001: Using El Niño/Southern Oscillation Climate Data to Predict Rice Production in Indonesia. Clim. Change 50, 255-265.

Pacanowski, R. C., and S. M. Griffies, 1998: MOM 3.0 manual. NOAA/Geophysical Fluid Dynamics Laboratory, Princeton, NJ, 608pp.

Roberts, G. M., D. David, F. P. Walter, N. L. Rosamond. 2009: El Niño-Southern Oscillation Impacts on Rice Production in Luzon, the Philippines. J. Appl. Meteor., 48, 1718-1724.

Roeckner, E.,, and Coauthors, 1996: The atmospheric general circulation model ECHAM4: Model description and simulation of present day climate. Rep. 218, Max-Planck-Institut für Meteorologie, $90 \mathrm{pp}$.

Saha, S., S. Nadiga, C. Thiaw, J. Wang, W. Wang, Q. Zhang, H.M. Van Den Dool, H.-L. Pan, S. Moorthi, D. Behringer, D. Stokes, M. Pena, S. Lord, G. White,W. Ebisuzaki, P. Peng, and P. Xie, 2006:The NCEP Climate Forecast System. J. Climate 19, 3483-3517.

Selvaraju, R., 2003: Impact of El Niño -Southern Oscillation on Indian foodgrain production. Int. J. Climatol., 23, 187-206. 
Swets, J. A., 1973: The relative operating characteristic in psychology. Science, 182, 990-1000.

Van den Dool, H. M., 1994: Searching for analogues, how long must we wait? Tellus, 46A, 314 324.

Wang, B., R. Wu, and K.-M. Lau, 2001: Interannual variability of the Asian summer monsoon: Contrasts between the Indian and the western North Pacific-East Asian monsoons. $J$. Climate, 14, 4073-4090.

Wang B, Ho L., 2002: Rainy season of the Asian-Pacific summer monsoon. J Climate, 15, 386398.

Wu, R., and B. Wang, 2000: Interannual variability of summer monsoon onset over the western North Pacific and the underlying processes. J. Climate, 13, 2483-2501. 


\section{List of Figures}

Figure 1. (a) Annual rice production, (b) yield, and (c) area harvested of all ecosystems (blue), irrigated systems (red), and rainfed systems (pink) in the Philippines (1970-2007).

Figure 2. (a) Annual rice production and (b) percentages of irrigated production in 2007.

Figure 3. (a) Locations of 77 PAGASA rainfall stations used in the analysis (red, blue, yellow, and green dots represent climate types I, II, III, and IV respectively), and (b) Region names and numbers.

Figure 4. SAI (solid lines) and DOF (dotted lines) for seasonal amount (blue), occurrence of rainfall (red), and mean intensity of rainy days (pink) of the 77-station network.

Figure 5. Correlation between Nino 3.4 SSTAs and SAI for seasonal amount (blue), occurrence of rainfall (red), and mean intensity (pink) of rainy days of the 77-station network. The dashed lines indicate $95 \%$ confidence levels.

Figure 6. Lag correlation of dry-season rice production ((a)-(c)), yield ((d)-(f)), and area harvested ((g)-(i)) of the Philippines (blue bold) and each of the 16 regions (pink), with SAI of seasonal amount from DJF of year (-1) to JJA of year(0). The dashed lines indicate $95 \%$ confidence levels.

Figure 7. Cross-validated anomaly correlation skills of dry-season all-ecosystem rice production, based on the predictors given the legend. The vertical line indicates the start of the riceproduction season in January. Each point represents the skill value of forecasts made in that month. See text for details.

Figure 8. Dry-season de-trended observed all-ecosystem national rice production (blue), together with retrospective GCM-based forecast values from the CFS (red with dots) and 
ECHAM4.5-MOM (green with dots) GCMs, initialized on the previous June 1.

Figure 9. ROC diagram for forecasts of the above/below normal tercile categories of national rice production in the dry season, based on ECHAM4.5-MOM forecasts initialized on June 1 st.

Figure 10. Cross-validated anomaly correlation skills for dry-season all-ecosystem rice production at (a) the regional level, and (b) the provincial level, based on ECHAM4.5-MOM retrospective forecasts initialized on $1^{\text {st }}$ June. Provinces without rice production data are shaded.

Figure 11. Lag correlation of rainy-season rice production ((a)-(c)), yield ((d)-(f)), and area harvested ((g)-(i)) of the Philippines (blue bold) and each region (pink), with SAI of seasonal amount from JJA of year (-1) to DJF of year(0). The dashed lines indicate $95 \%$ confidence levels.

Figure 12. Correlations between the rainy-season yields in (a) irrigated rice systems with SAI of seasonal rainfall amounts in OND of year (0) . (b) is same as (a) except for July-December accumulated cyclone energy (ACE).

Figure 13. Cross-validated anomaly correlation skills for rainy-season all-ecosystem national rice production, and for Luzon, based on antecedent observed values of Nino 3.4, and WWV and $\mathrm{ZW}$, averaged over the months preceding the forecast time (abscissa). The vertical line indicates the start of the rice-production season in July. Negative values omitted.

Figure 14. Rainy-season de-trended observed all-ecosystem rice production for the Philippines (blue solid) and Luzon (green solid), together with forecasted values derived using MLR of WWV and ZW in the previous DJF (dotted blue and green lines respectively).

Figure 15. Cross-validated anomaly correlation skills for rainy-season all-ecosystem rice production at (a) the regional level, and (b) and provincial level (b). The WWV and ZW in 
previous DJF were used as predictors.

Figure 16. ROC diagram for forecasts of the above/below normal tercile categories of rainyseason all-ecosystem Luzon rice production, based on WWV and ZW in the previous DJF. 

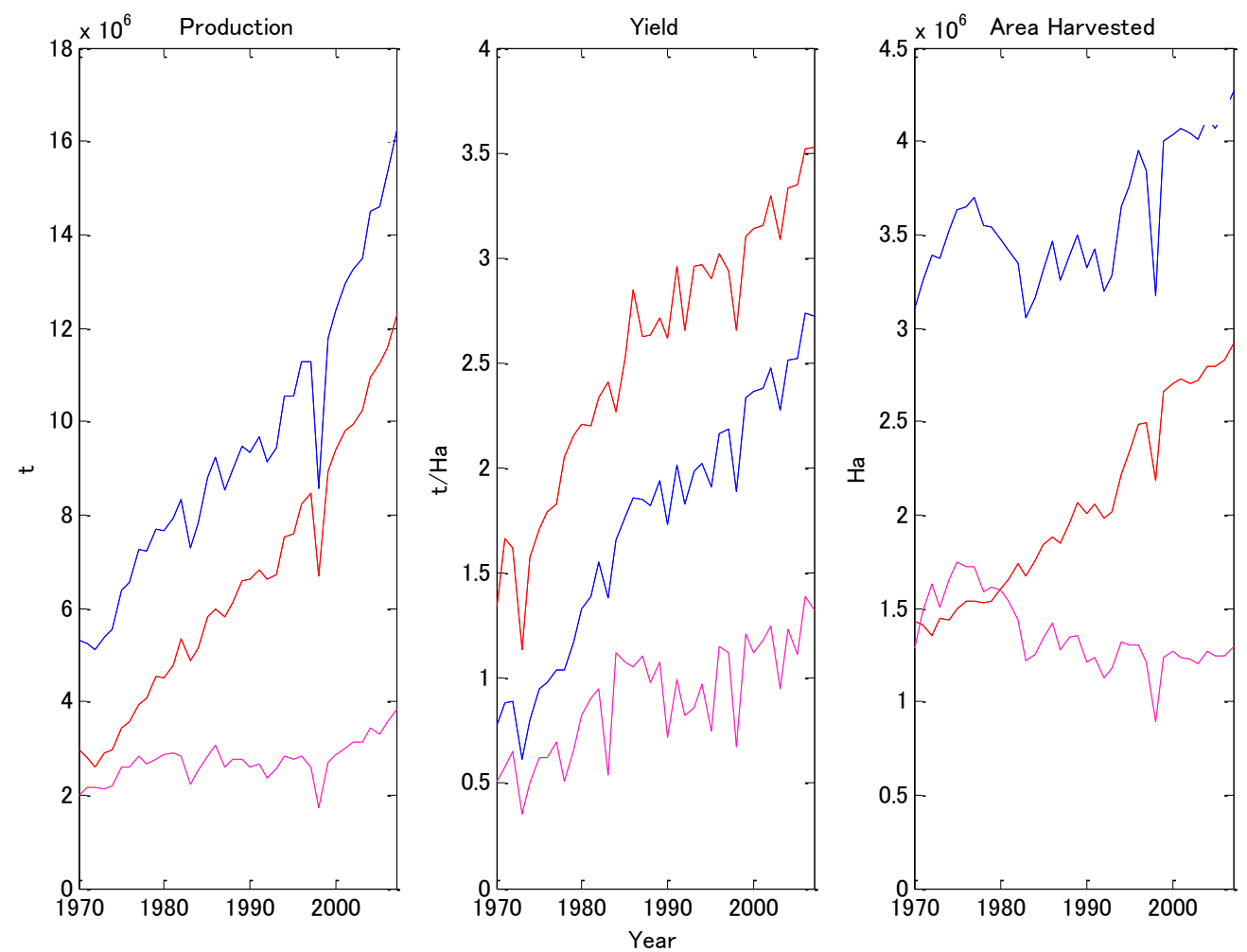

Figure 1. (a) Annual rice production, (b) yield, and (c) area harvested of all ecosystems (blue), irrigated systems (red), and rainfed systems (pink) in the Philippines (1970-2007). 


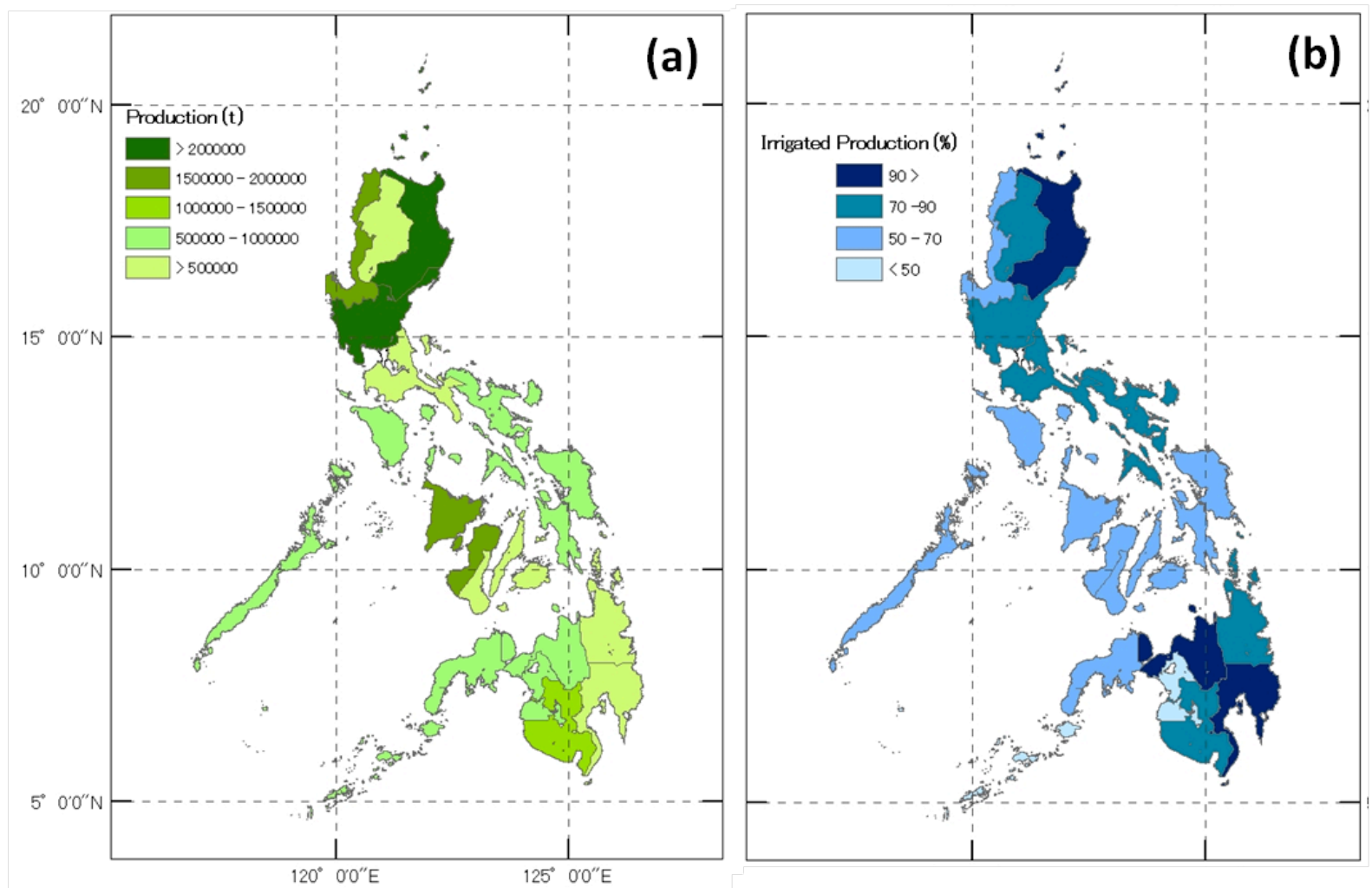

Figure 2. (a) Annual rice production and (b) percentages of irrigated production in 2007. 

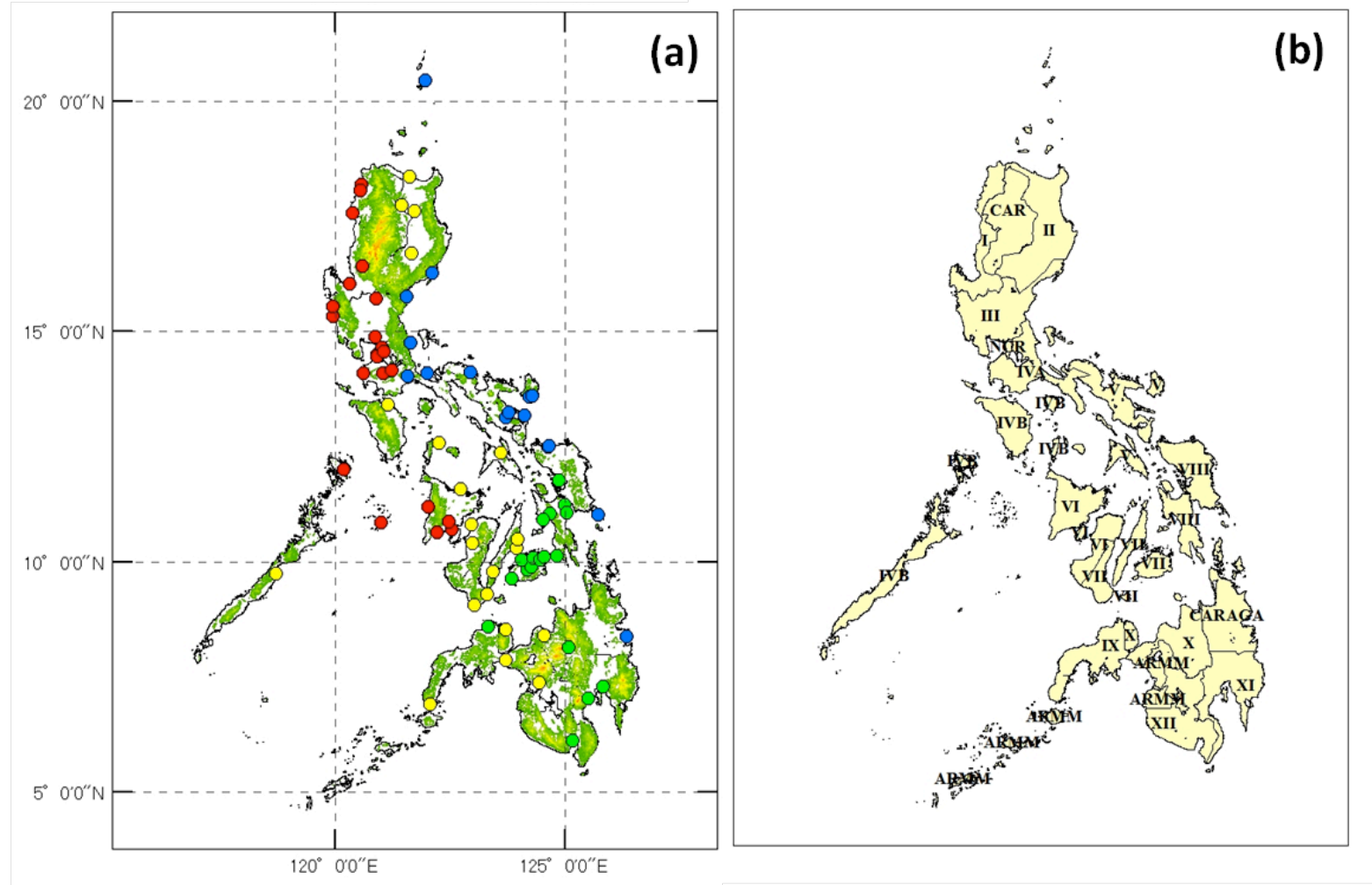

Figure 3. (a) Locations of 77 PAGASA rainfall stations used in the analysis (red, blue, yellow, and green dots represent climate types I, II, III, and IV respectively), and (b) Region names and numbers. 


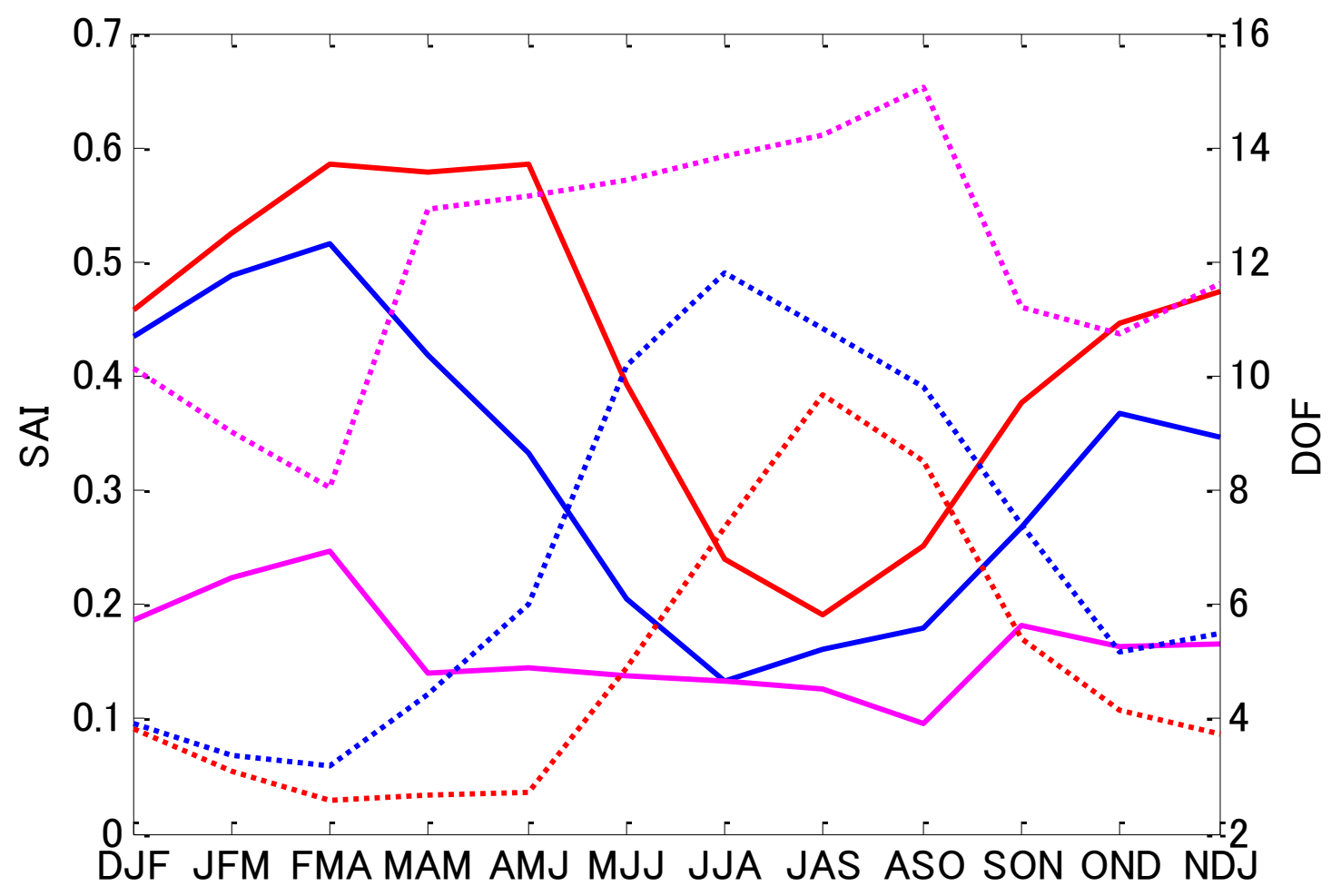

Figure 4. SAI (solid lines) and DOF (dotted lines) for seasonal amount (blue), occurrence of rainfall (red), and mean intensity of rainy days (pink) of the 77-station network. 


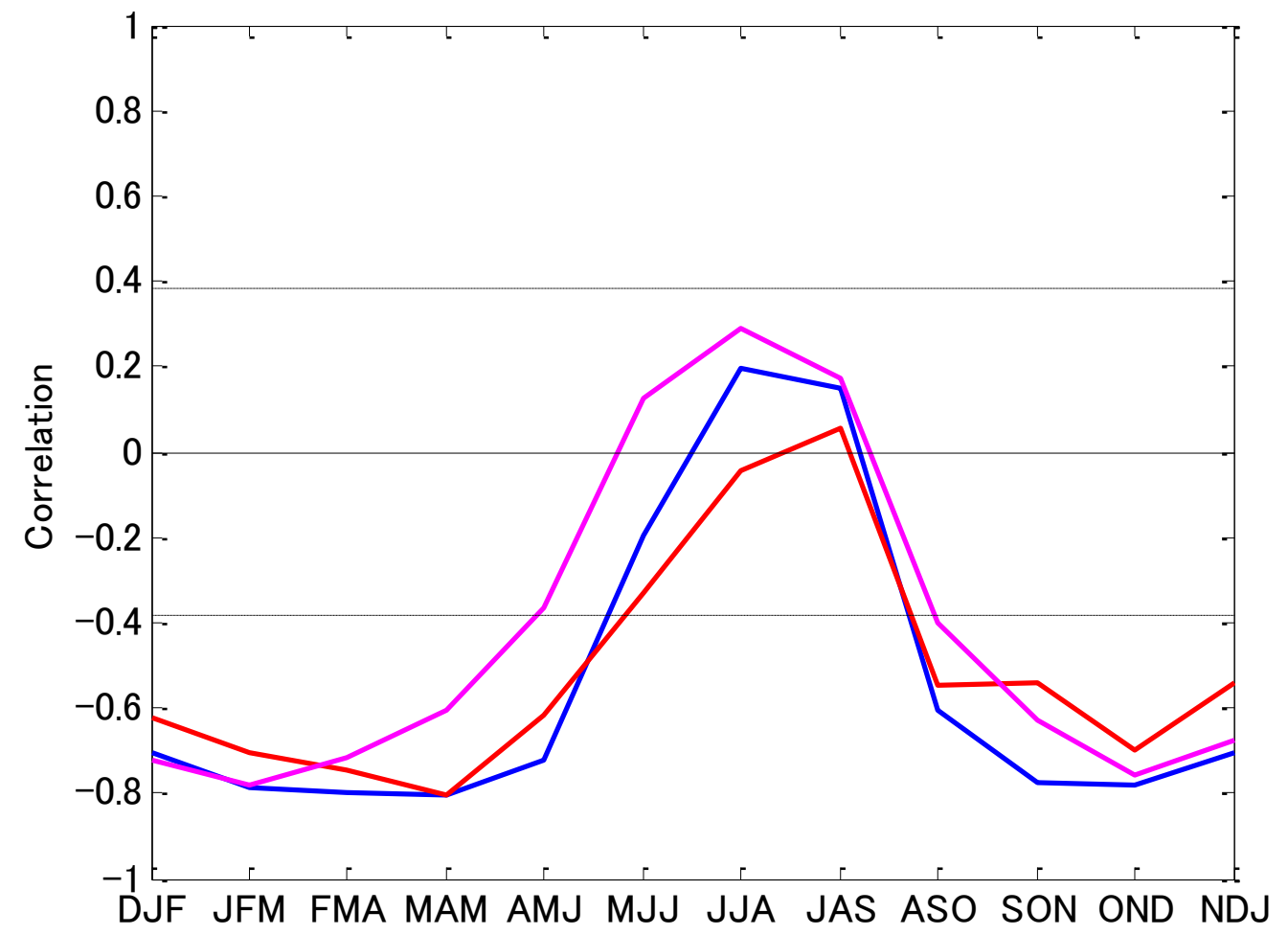

Figure 5. Correlation between Nino 3.4 SSTAs and SAI for seasonal amount (blue), occurrence of rainfall (red), and mean intensity (pink) of rainy days of the 77-station network. The dashed lines indicate $95 \%$ confidence levels. 
(d)
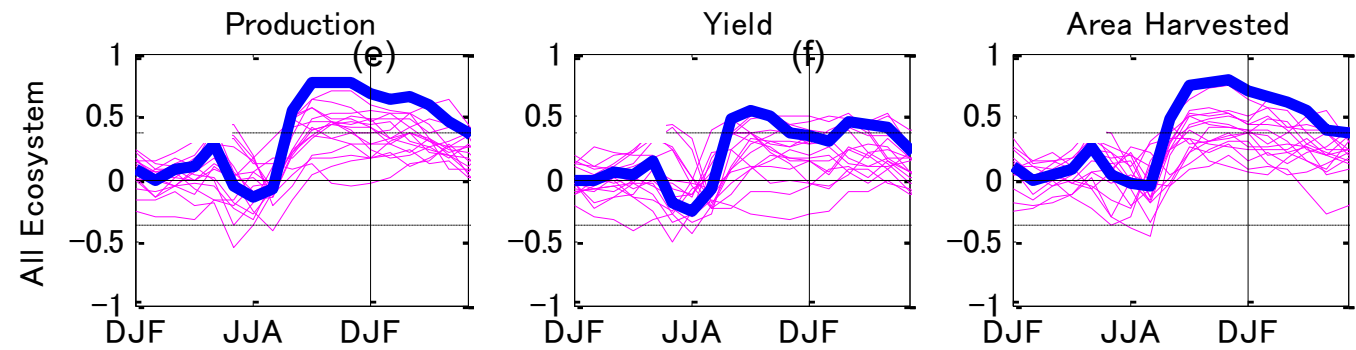

(g)
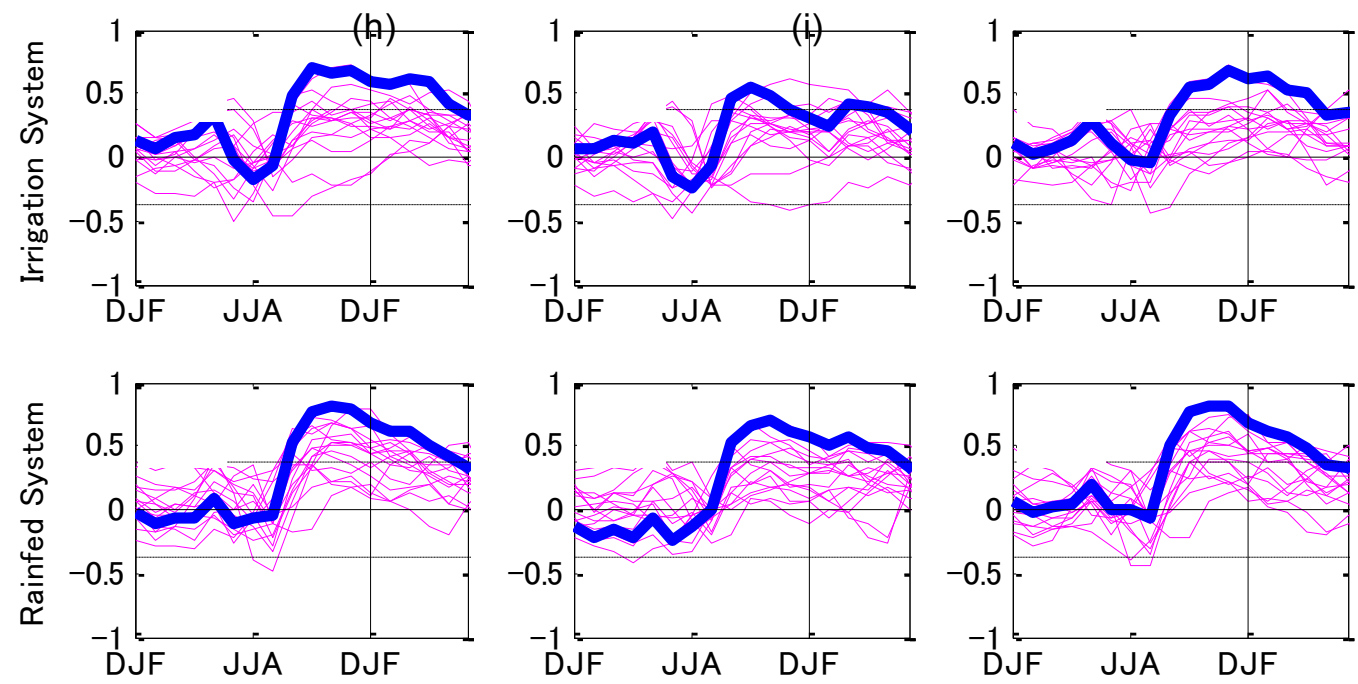

Figure 6. Lag correlation of dry-season rice production ((a)-(c)), yield ((d)-(f)), and area harvested ((g)-(i)) of the Philippines (blue bold) and each of the 16 regions (pink), with SAI of seasonal amount from DJF of year (-1) to JJA of year(0). The dashed lines indicate $95 \%$ confidence levels. 


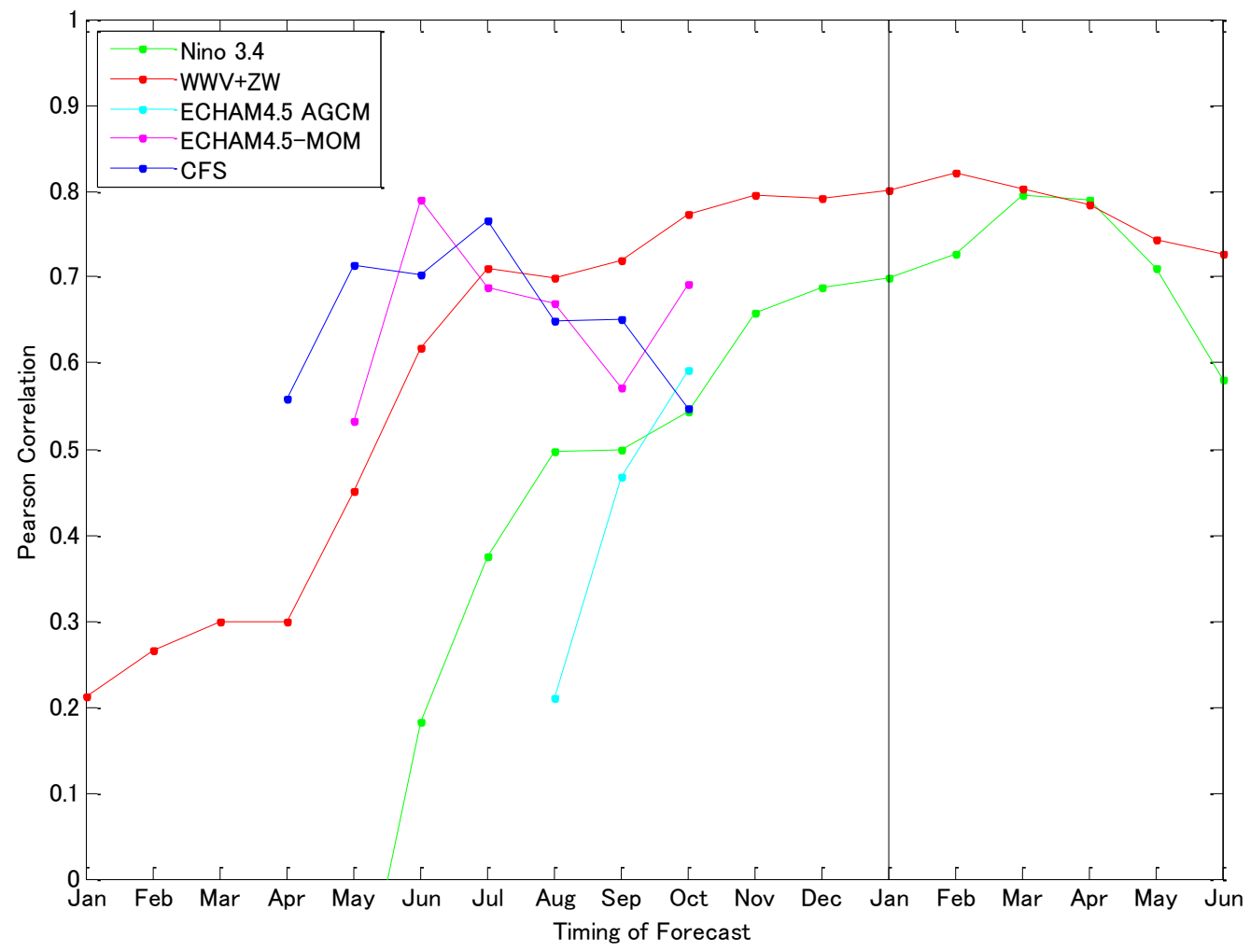

Figure 7. Cross-validated anomaly correlation skills of dry-season all-ecosystem rice production, based on the predictors given the legend. The vertical line indicates the start of the riceproduction season in January. Each point represents the skill value of forecasts made in that month. See text for details. 


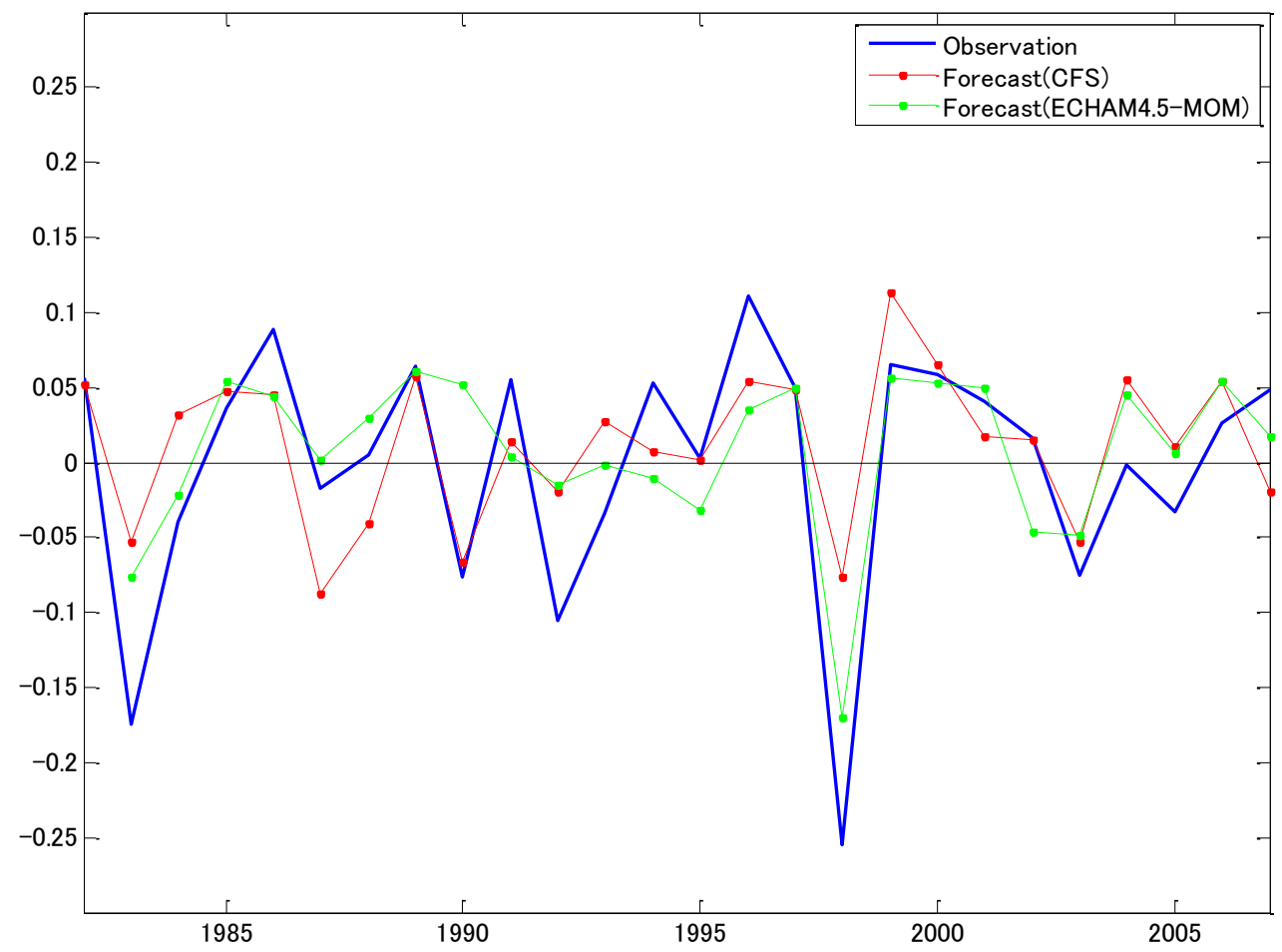

Figure 8. Dry-season de-trended observed all-ecosystem national rice production (blue), together with retrospective GCM-based forecast values from the CFS (red with dots) and ECHAM4.5MOM (green with dots) GCMs, initialized on the previous June 1. 


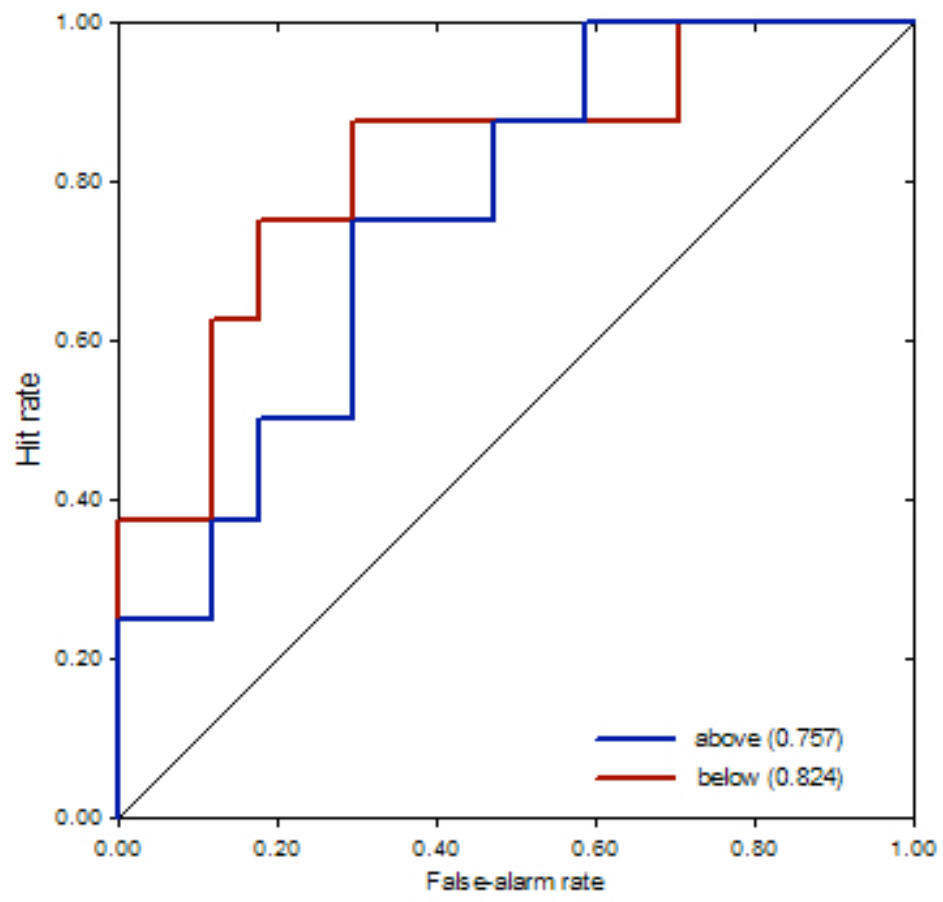

Figure 9. ROC diagram for forecasts of the above/below normal tercile categories of national rice production in the dry season, based on ECHAM4.5-MOM forecasts initialized on June 1 st. 


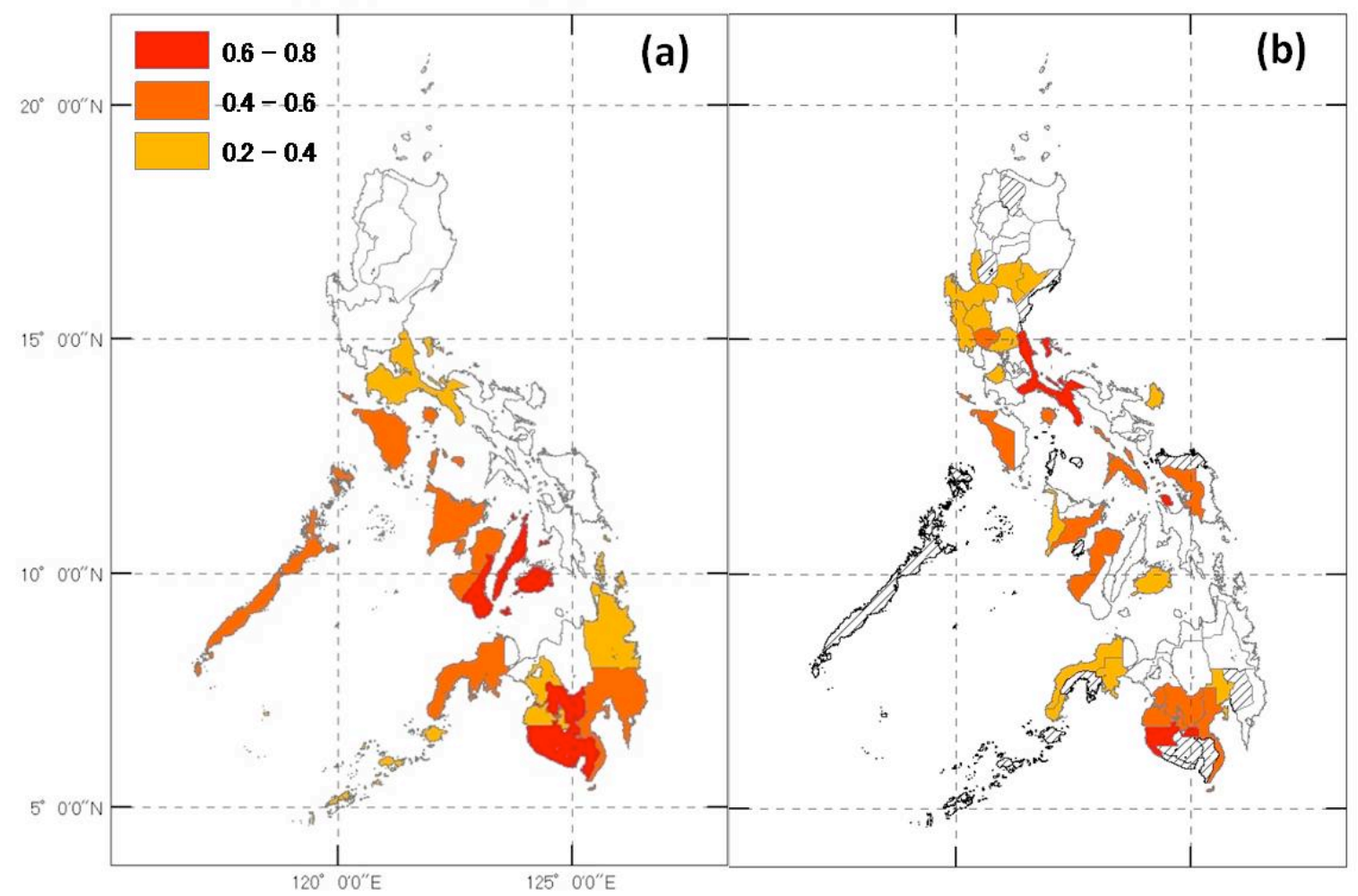

Figure 10. Cross-validated anomaly correlation skills for dry-season all-ecosystem rice production at (a) the regional level, and (b) the provincial level, based on ECHAM4.5-MOM retrospective forecasts initialized on $1^{\text {st }}$ June. Provinces without rice production data are shaded. 

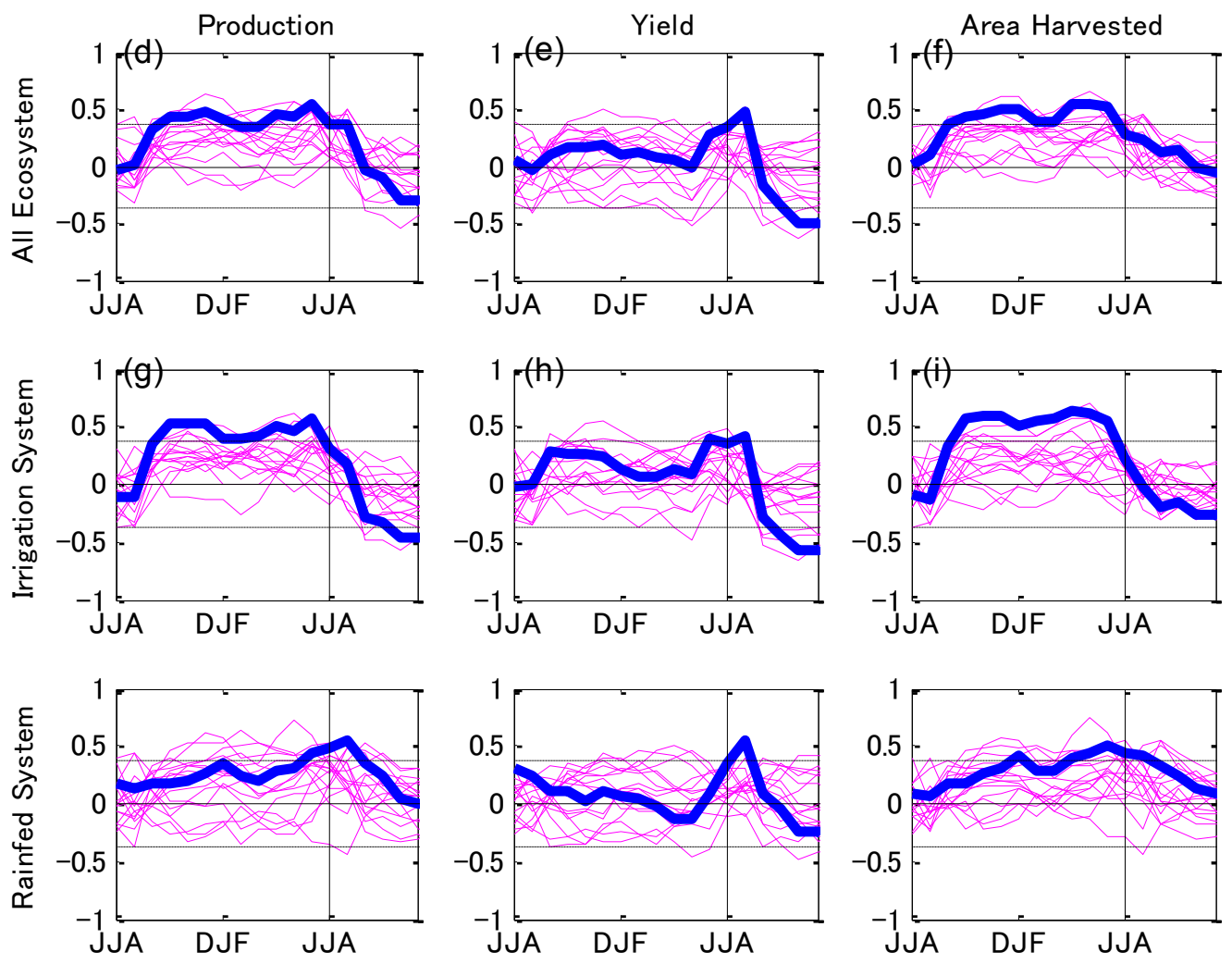

Figure 11. Lag correlation of rainy-season rice production ((a)-(c)), yield ((d)-(f)), and area harvested ((g)-(i)) of the Philippines (blue bold) and each region (pink), with SAI of seasonal amount from JJA of year (-1) to DJF of year(0). The dashed lines indicate $95 \%$ confidence levels. 


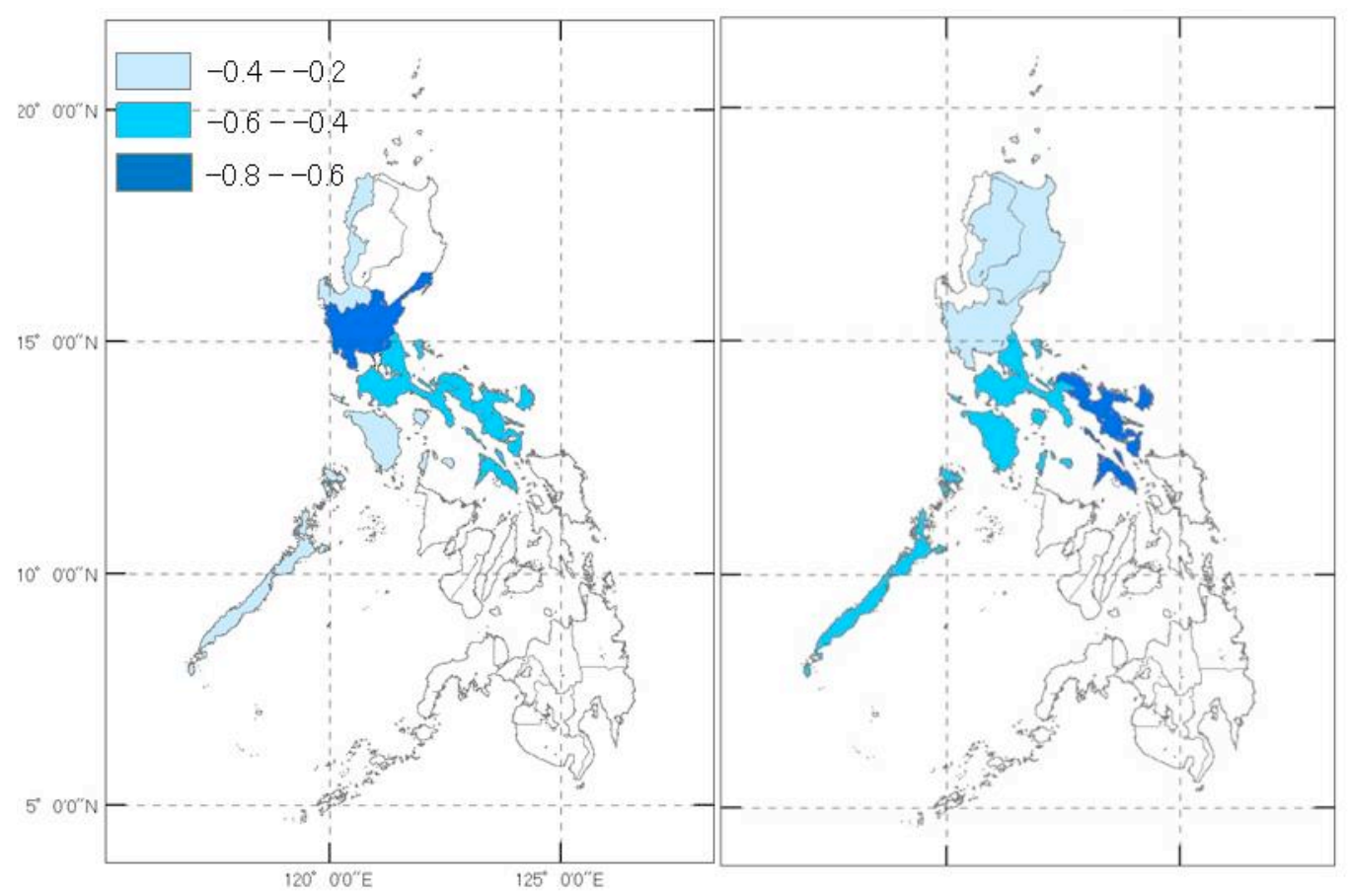

Figure 12. Correlations between the rainy-season yields in (a) irrigated rice systems with SAI of seasonal rainfall amounts in OND of year (0) . (b) is same as (a) except for July-December accumulated cyclone energy (ACE). 


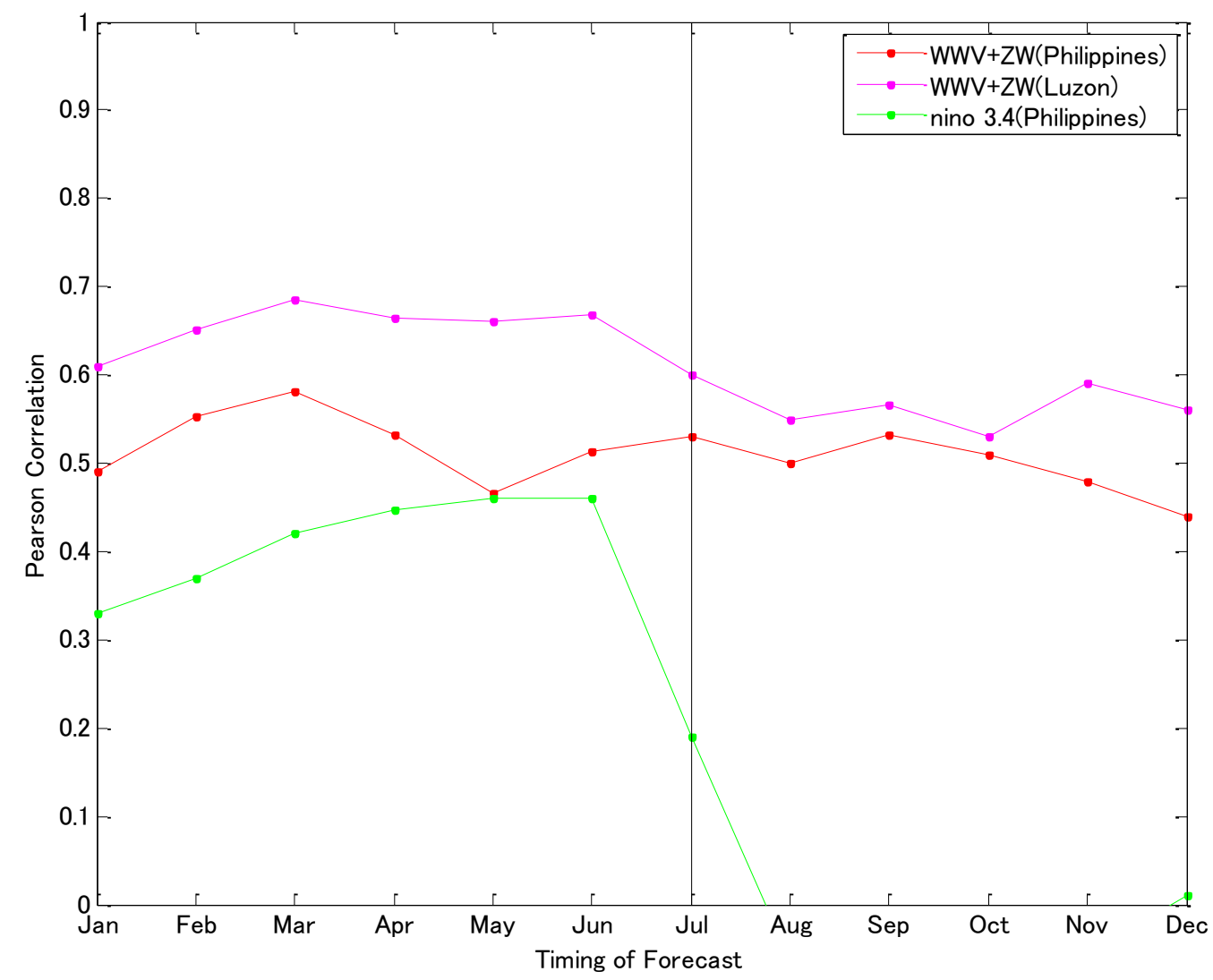

Figure 13. Cross-validated anomaly correlation skills for rainy-season all-ecosystem national rice production, and for Luzon, based on antecedent observed values of Nino 3.4, and WWV and ZW, averaged over the months preceding the forecast time (abscissa). The vertical line indicates the start of the rice-production season in July. Negative values omitted. 


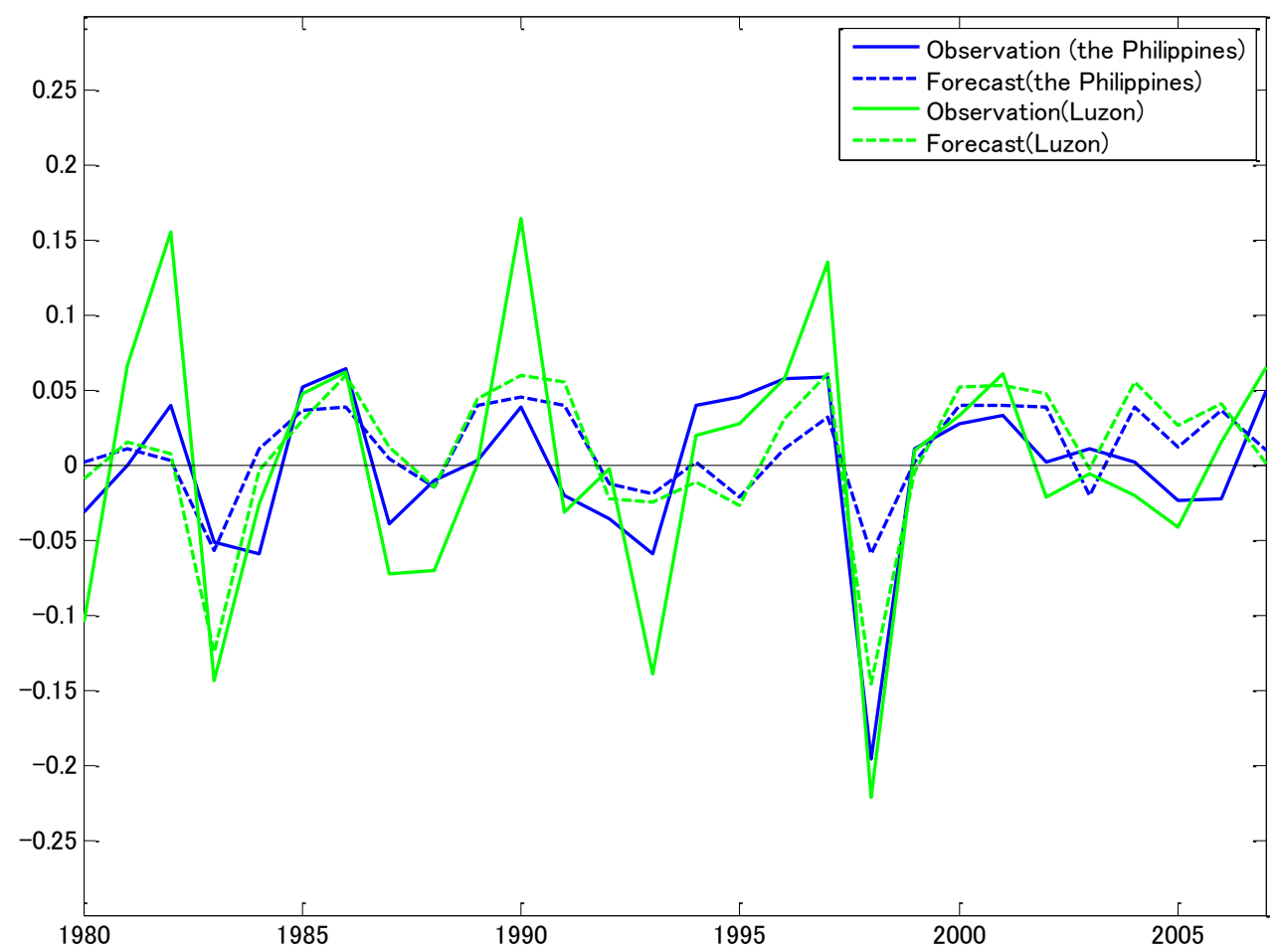

Figure 14. Rainy-season de-trended observed all-ecosystem rice production for the Philippines (blue solid) and Luzon (green solid), together with forecasted values derived using MLR of WWV and ZW in the previous DJF (dotted blue and green lines respectively). 

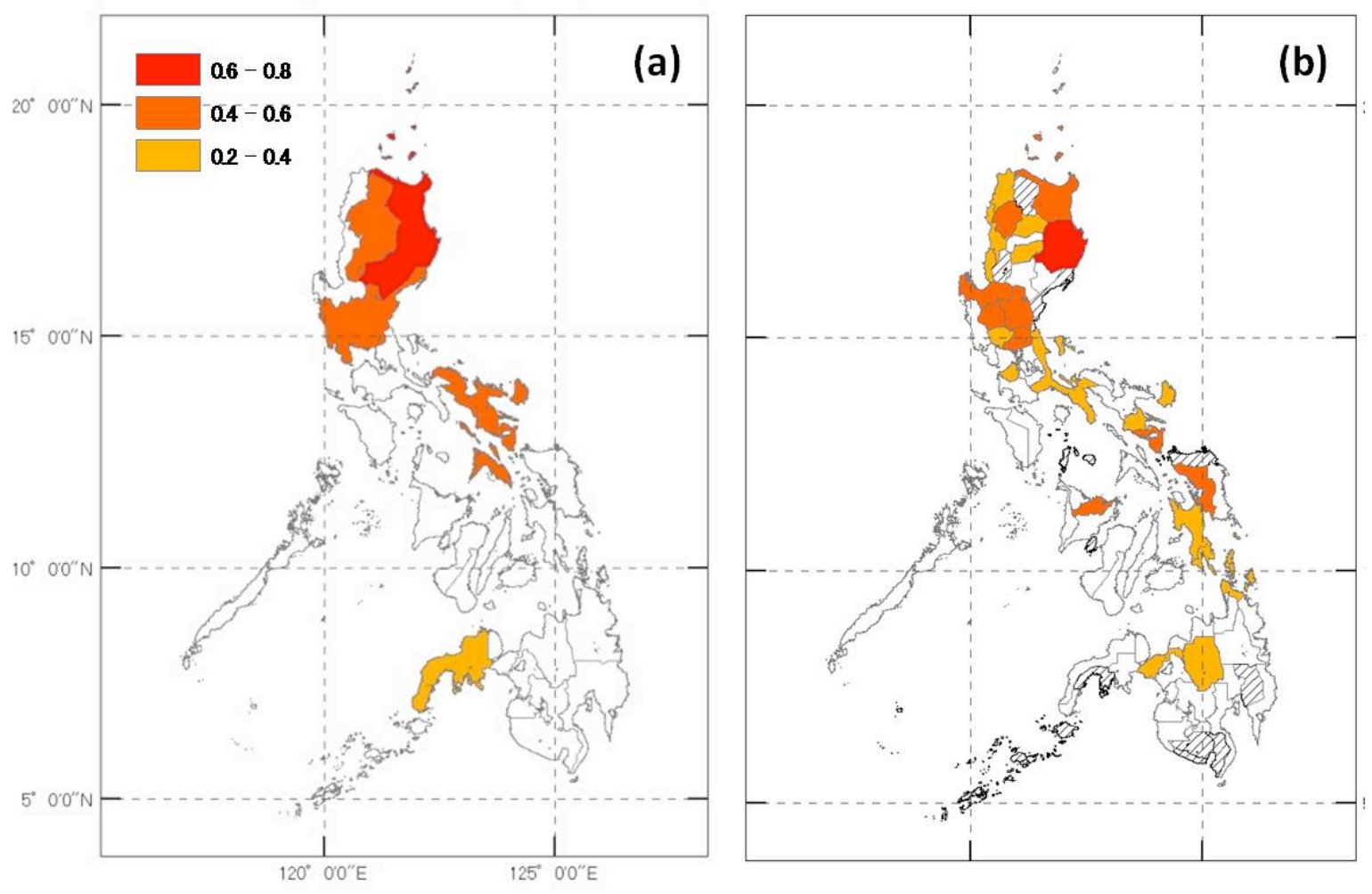

Figure 15. Cross-validated anomaly correlation skills for rainy-season all-ecosystem rice production at (a) the regional level, and (b) and provincial level (b). The WWV and ZW in previous DJF were used as predictors. 


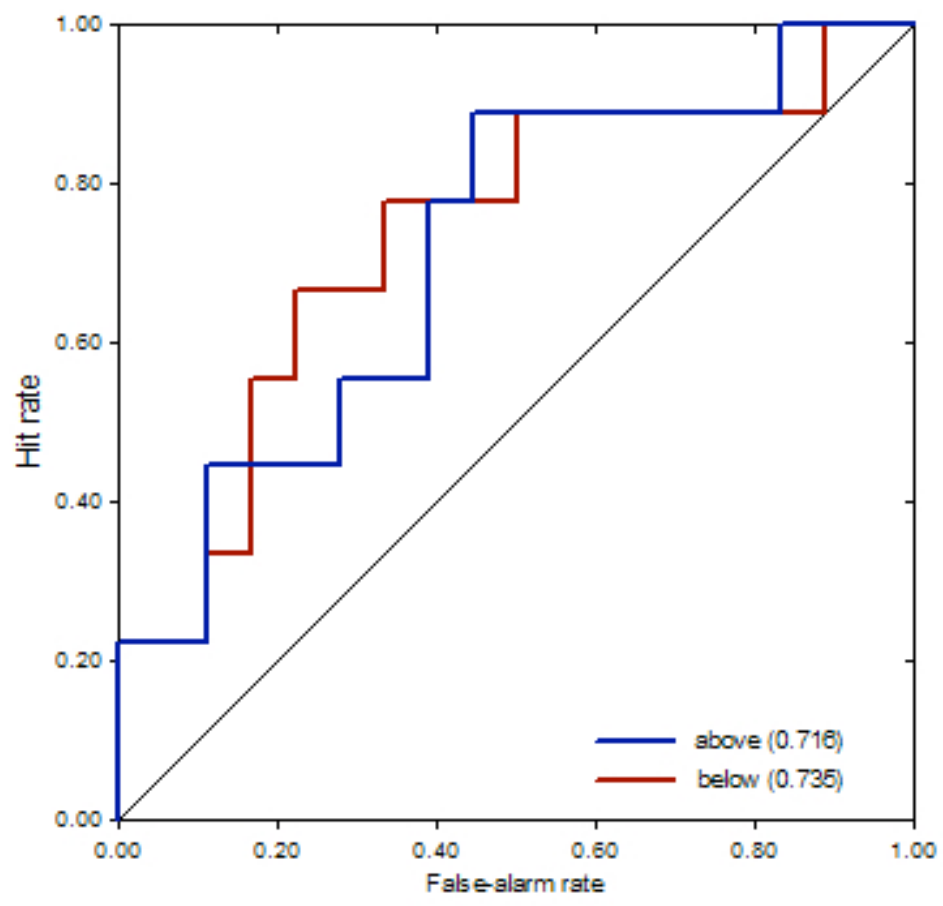

Figure 16. ROC diagram for forecasts of the above/below normal tercile categories of rainyseason all-ecosystem Luzon rice production, based on WWV and ZW in the previous DJF. 